\title{
Inflation trends in Asia: implications for central banks
}

\author{
Juan Angel Garcia ${ }^{a}$ and Aubrey Poon
}

${ }^{a}$ European Central Bank, Capital Markets and Financial Structure Division, DG-MP, Sonnemannstrasse 20, Frankfurt am Main 60314, Germany; e-mail: juan_angel.garcia@ecb.europe.eu ${ }^{b}$ Department of Economics, University of Strathclyde, 199 Cathedral Street, Glasgow G4 OQU, UK;

e-mail: aubrey.poon@strath.ac.uk

\begin{abstract}
This article shows that trend inflation estimation offers crucial insights for the analysis of inflation dynamics and long-term inflation expectations. Focusing on the 12 largest Asian economies, a sample comprising both advanced and emerging economies and different monetary policy regimes, we show that trend inflation analysis can help explain the different impact of the disinflationary shocks across countries. Among countries with inflation below target in recent years, in those with trend inflation low but constant (Australia, New Zealand) low inflation may be lasting, but temporary, while those in which trend inflation has declined (South Korea, Thailand) risk low inflation to become entrenched and a de-anchoring of expectations. Countries like India, Philippines, and Indonesia instead experienced a moderation in inflation and lower trend inflation, while others (China, Taiwan, Hong Kong SAR, Malaysia) were impacted very mildly. That diverse international evidence offers important insights for central banks worldwide.
\end{abstract}

JEL classifications: C11, C32, E31, F41

\section{Introduction}

Uncertainty about inflation dynamics has resurfaced in recent years: both the missing disinflation in the aftermath of the global financial crisis (GFC) and the missing inflation after the recovery have triggered controversy about inflation behaviour in many countries worldwide (e.g. IMF, 2013, 2016). Indeed, not only a large number of advanced economies (AEs) but also some emerging economies (EMs) have experienced protracted periods of rather subdued core inflation and below-target inflation. Against this background, long-term inflation expectations have also received a lot of attention. The monetary transmission mechanism is most effective when inflation expectations are strongly anchored, and the expectations channel has become a crucial mechanism for inflation to return to target. Yet, survey long-term inflation expectations have changed very little from their pre-GFC levels, 
which has cast some doubts about their potential disconnection from actual inflation developments. Those puzzles point to a need to improve inflation analysis to allow for a successful implementation of monetary policy.

This article investigates developments in headline inflation and inflation expectations through the lens of trend inflation. Specifically, we decompose observed inflation rates into a trend, or permanent component, and a transitory, or (cyclical) inflation gap in the spirit of Beveridge-Nelson. The central bank's capacity to distinguish between permanent and transitory influences in inflation rates is crucial for the appropriate monetary policy stance. Misinterpreting lasting inflationary pressures by merely transitory moves in inflation may set inflation on a course-in either direction - that may become much more difficult to revert in the future, turn out costly in terms of economic activity, and harm central bank credibility. Gauging underlying inflationary pressures nonetheless remains challenging, and we show that trend inflation estimation provides valuable information for monetary policy beyond standard core inflation measures.

Trend inflation is estimated using an extension of the unobserved component and stochastic volatility (UCSV) model of Stock and Watson (2007). Importantly, to account for the important role of inflation expectations in inflation dynamics, survey measures are incorporated into the estimation. Following Chan et al. (2018), our model exploits the forward-looking information of survey expectations, but, importantly, allows for the potential level of trend inflation and the reported level of survey inflation expectations to differ over time.

We apply our model to the interpretation to the experiences of Asian economies. Asia has been the world's most dynamic economic area over the last few decades. However, inflation research for the region arguably lags somewhat behind that available for trade, exchange rates, and capital flows or growth. This article contributes to fill that void. We estimate trend inflation for 12 of the largest Asian economies, six AEs (Australia, Hong Kong, Japan, Korea, New Zealand, and Taiwan) and six EMs (China, Indonesia, India, Malaysia, Philippines, and Thailand) over the last three decades. Most Asian central banks have undertaken significant improvements in their monetary policy frameworks over our sample. While differences across monetary policy regimes persist, the improvements in monetary policy frameworks helped the region weather relatively well the GFC. Asian economies, with the exception of Japan, had not been generally affected by low inflation until recently, but, particularly since 2014 , inflation has also been persistently below target in many countries in the region despite quite a robust growth, which make Asia a very interesting region for the study of potential changes in inflation dynamics.

Our analysis shows that trend inflation estimation offers important insights for central banks regardless of differences in inflation objectives and monetary policy regimes. Our country sample comprises some AEs with a sound reputation as inflation targeters (e.g. Australia, New Zealand), countries that have struggled with low inflation for long (e.g. Japan) or in more recent years (e.g. South Korea, Thailand), and EMs still afflicted by relatively high inflation (e.g. India).

Our main findings are as follows. First, a decomposition of Asian inflation into a trend and transitory components shows that the bulk of the decline in inflation in the region over the last two decades is explained by lower trend inflation. Interestingly, both AEs and EMs contributed to the lower trend inflation in the region, although the decline in the former group of countries was relatively milder than in the latter. 
Secondly, we show that trend inflation estimates can offer new insights about the degree of anchoring of inflation expectations and its changes over time. By construction, trend inflation reflects the inflation rate to be observed once the transitory inflation influences die away, and can therefore be interpreted as the optimal conditional long-term inflation forecast. We use our trend inflation estimates as benchmarks for comparison to the level of survey long-term inflation expectations, and the announced (mid-point if a band) level of the central bank target. For example, our country-level analysis identifies different responses of inflation expectations to the below-target inflation rates observed in some countries in the region over 2014-7. While countries like Australia and New Zealand continue to exhibit strong anchoring of inflation expectations, a more significant weakening can be observed, for example, in South Korea and Thailand. Importantly, trend inflation helps to understand both actual inflation and inflation expectations in all those countries, and their experiences are likely to offer important lessons for other economies.

This article contributes to the growing literature that estimates trend inflation using UCSV models such as Chan et al. (2013); Mertens (2015); and Forbes (2019b) among others. By focusing on 12 of the largest Asian economies, our analysis expands existing international evidence on the estimation of trend inflation, in line with Garnier et al. (2015) for AEs, but also including some important EMs. In particular, our evidence on the Asian economies illustrates that protracted periods of persistent below-target inflation can also take place even against fairly sound rates of growth and also in large EMs like Thailand, and how low inflation can affect the anchoring of inflation expectations. Our findings are complementary to the results in Kamber and Wong (2020), where global factors on inflation are shown to reflect commodity price shocks and mainly affect the inflation gap, while trend inflation remains mostly driven by domestic monetary policy (see also Forbes, 2019a).

Our analysis of inflation expectations also contributes to the literature on expectation formation (for a recent overview, see Coibion et al., 2018). Trend inflation estimation helps to assess survey expectations over long-term horizons, while most literature has predominantly focused on shorter horizons (often just 1-2 years ahead). Trend inflation estimation allows us to gauge potential shifts in the anchoring of inflation expectations over time, a task that is performed regularly at many central banks and international institutions (e.g. IMF, 2018b). In addition, our analysis of survey inflation expectations among the largest Asian economies offers new international evidence for the debate on expectation formation.

This article is organized as follows. Section 2 discusses the motivation for trend inflation estimation and provides an overview of the different approaches that have been proposed in the literature. Section 3 describes inflation developments in Asia over our sample. Our empirical framework for the estimation of trend inflation is described in Section 4, and a regional perspective is offered in Section 5. We elaborate on the insights trend inflation modelling offers for inflation and expectations analysis in Section 6, and discuss individual country experiences in Section 7. Section 8 finally concludes.

\section{Core and trend inflation: an overview of the literature}

Inflation developments are nowadays closely monitored by central banks and market participants. Headline inflation readings tend to be volatile and gauging the underlying inflationary pressures present in an economy at a given point in time is often needed. While 
there is wide consensus on the usefulness of the underlying inflation concept, there is less agreement on the optimal approach to gauge trend inflation.

Broadly speaking, existing approaches can be classified in two main categories. The first approach restricts the influence of theCost price index (CPI) components associated to nonpersistent fluctuations to construct measures of 'core' inflation, which usually excludes food and energy prices. Core inflation measures became popular in the 1970s, when large price movements in food and oil complicated the interpretation of headline inflation (see Gordon, 1975; Eckstein, 1981, for early contributions and Wynne, 2008, for a historical overview). Other versions include trimmed mean and median inflation measures (e.g. Bryan and Cecchetti, 1994), which restrict the volatility of inflation by excluding the components displaying the largest changes-in any direction-in a given month.

While core inflation measures are easy to construct and to understand, they also have some important shortcomings. First, their usefulness hinges on the source of transitory influences (e.g. energy and food prices) being constant over time, and some potential changes in inflation over time that may be crucial to gauge the persistent component of inflation can be ignored. Similarly, excluding components that display large price changes through trimmed mean and median measures may also remove useful information of changes in trend inflation. Rich and Steindel (2007) compare several core inflation measures in the USA and conclude that their performance varies with the sample due to the fact that there is considerable variability in the nature and sources of transitory price movements.

For a multi-country perspective like ours, core inflation measures also pose an additional problem. Excluding mechanically energy and food components from the official CPI index may imply removing a very different percentage of the consumption basket across countries, for the CPI basket composition is country-specific. For example, among the Asian countries we consider, removing food and transport prices would imply excluding about $26 \%$ of the consumer basket used in the CPI calculation in Australia, while excluding similar basket components in Thailand would be above $27 \%$, more than $29 \%$ in Malaysia, almost $50 \%$ in India, but only about $21 \%$ in South Korea.

The second approach uses model-based techniques, including univariate time series (e.g. Atkeson and Ohanian, 2001; Cogley, 2002), and multivariate macromodels like Gordon (1990) 'triangle'-type models. More recently, and to a large extent motivated by some puzzles on inflation developments and long-term inflation expectations after the GFC, there has been a renewed interest on the estimation of trend inflation using UCSV models, mainly for the US economy, although some evidence is also available for several AEs (e.g. Garnier et al., 2015), and the euro area (e.g. Garcia and Poon, 2018).

Our empirical approach follows Chan et al. (2018), where, building on earlier work (e.g. Kozicki and Tinsley, 2012) long-term survey measures (6-10 years ahead) are incorporated into the estimation of trend inflation to account for the important role of expectations in inflation dynamics. Our survey data are from Consensus Economics, a widely used source in most central banks and international organizations (e.g. see IMF, 2018b). ${ }^{1}$ Trend

1 Consensus Economics, established in 1989, now surveys leading professional forecasters in more than 115 economies. In the Asia Pacific region, Consensus Forecasts collects information from over 180 prominent forecasters for 18 countries. In particular, inflation expectations are collected over several different horizons (mostly year averages, that is fixed calendar horizons, but also quarterly short-term forecasts with rolling horizons). In this article, we will use inflation forecasts for 
and survey measures are not equated by assumption, but can differ over time, which allows for assessing survey expectations.

\section{An overview of inflation developments in Asia 1996-2018}

Before discussing trend inflation analysis, Table 1 provides some descriptive statistics for the monthly year-on-year headline inflation rates between 1995 and 2018 (panel A), and core inflation (excluding food and energy prices, panel B) following the national definitions. $^{2}$

Table 1 documents the significant heterogeneity in the inflation experiences among Asian economies. Over the last two decades inflationary pressures appear to be very well contained among AEs, probably reflecting their early introduction of inflation targeting (e.g. New Zealand in 1990, Australia in 1993, Korea in 1998). EMs in Asia have, in contrast, experienced higher average and more volatile inflation. All Asian countries have however experienced both some inflation spikes and also low inflation episodes. High-inflation episodes tend to be concentrated in the earlier years of our sample in most cases, while negative or very low-inflation rates used to be normally associated to cyclical downturns. Finally, while for many countries those severe deflationary episodes took place in the aftermath of the AFC, most of them have weathered relatively well the disinflationary pressures following the GFC. Somewhat surprisingly, however, inflation in some Asian countries (e.g. Thailand, Korea, New Zealand) appeared to be more vulnerable to the protracted decline in commodity prices over 2014-6.

Core inflation is somewhat less volatile than the headline. Yet, for most countries it also exhibits significant variations over time, which suggests that core inflation may still provide a rather noisy signal for monetary policy making. Further investigation in the role of different expenditure categories within the CPI basket is beyond the scope of this article. Evidence in IMF (2018a) suggests that the decline in inflation in Asia since 2011 has been fairly broad-based: declines across food, other goods, and services price inflation have been quantitatively similar, and across both tradable and non-tradable goods inflation as well. Importantly, such features are also shared by AEs and EMs in the region. ${ }^{3}$

\section{Econometric modelling of trend inflation}

Our UCSV model decomposes inflation $\pi_{t}$ into the trend inflation rate, $\pi_{t}^{*}$, and the temporary deviations of inflation from that trend, that is the (cyclical) inflation gap $\pi_{t}-\pi_{t}^{*}$. In this context, trend inflation reflects the most likely inflation rate to be observed once the transitory influences on inflation die away, and can therefore be interpreted as the optimal

the longest horizon surveyed, $6-10$ years ahead, which should be free from transitory inflation influences as our trend inflation estimates. Collected at quarterly frequency, they are regularly used by many central banks and researchers.

2 The start of the sample is motivated by the availability of survey long-term measures of inflation expectations in most countries in the region.

3 Eo et al. (2020) introduces a two-sector (goods and services) model of trend inflation for the U.S. Canada and Australia, and finds that variation in trend inflation is nowadays mainly driven by service price developments, which is consistent with trend inflation being largely driven by domestic forces (see also Kamber and Wong, 2020) and provides support for our focus in this article. 
Table 1. Inflation in Asia: basic statistics.

A. Headline inflation

\begin{tabular}{lrrrrrrrr}
\hline Inflation & Mean & Median & St. deviation & Skewness & Kurtosis & Min. & Max. & Range \\
\hline Australia & 2.56 & 2.48 & 1.30 & 0.61 & 0.94 & -0.45 & 6.13 & 6.57 \\
Hong Kong SAR & 2.01 & 2.29 & 3.45 & -0.15 & -0.42 & -6.10 & 10.31 & 16.41 \\
Japan & 0.14 & -0.10 & 1.03 & 1.02 & 1.73 & -2.52 & 3.74 & 6.25 \\
Korea & 2.95 & 2.69 & 1.68 & 0.95 & 1.46 & 0.17 & 9.55 & 9.38 \\
New Zealand & 2.06 & 1.87 & 1.24 & 0.34 & -0.19 & -0.60 & 5.28 & 5.87 \\
Taiwan POC & 1.21 & 1.11 & 1.48 & 0.44 & 0.19 & -2.33 & 5.81 & 8.14 \\
China & 2.84 & 1.88 & 4.00 & 2.55 & 8.83 & -2.20 & 24.10 & 26.30 \\
India & 6.82 & 6.07 & 3.09 & 0.74 & 0.99 & 0.00 & 19.67 & 19.67 \\
Indonesia & 9.92 & 6.65 & 12.97 & 4.02 & 16.99 & -1.16 & 82.39 & 83.56 \\
Malaysia & 2.57 & 2.50 & 1.49 & 0.67 & 3.26 & -2.48 & 8.52 & 11.00 \\
Philippines & 4.80 & 4.41 & 2.33 & 0.59 & -0.28 & 0.35 & 10.70 & 10.34 \\
Thailand & 2.76 & 2.43 & 2.55 & 0.52 & 0.42 & -4.35 & 10.53 & 14.88
\end{tabular}

B. Core inflation (excluding food and energy)

\begin{tabular}{lrrrrrrrr}
\hline Core inflation & Mean & Median & St. Deviation & Skewness & Kurtosis & Min. & Max. & Range \\
\hline Australia & 2.53 & 2.40 & 0.95 & 1.52 & 3.26 & 0.73 & 6.75 & 6.02 \\
Hong Kong SAR & 1.73 & 1.89 & 3.89 & 0.00 & -0.29 & -7.86 & 10.88 & 18.74 \\
Japan & -0.06 & -0.20 & 0.87 & 1.14 & 1.19 & -1.70 & 2.42 & 4.12 \\
Korea & 2.78 & 2.56 & 1.39 & 0.78 & 0.79 & -0.35 & 7.44 & 7.79 \\
New Zealand & 1.78 & 1.72 & 0.71 & 0.34 & -0.53 & 0.34 & 3.58 & 3.25 \\
Taiwan POC & 0.74 & 0.64 & 1.07 & 0.95 & 2.13 & -2.26 & 5.05 & 7.31 \\
China & 1.25 & 1.50 & 0.91 & -1.62 & 2.48 & -1.60 & 2.50 & 4.10 \\
India & 6.67 & 6.61 & 2.63 & 0.30 & -0.19 & 0.87 & 14.69 & 13.82 \\
Indonesia & 5.51 & 4.93 & 1.80 & 0.88 & 0.01 & 2.98 & 10.20 & 7.23 \\
Malaysia & 2.48 & 2.44 & 0.50 & 1.42 & 1.22 & 1.96 & 3.57 & 1.60 \\
Philippines & 3.82 & 3.49 & 1.48 & 0.58 & -0.65 & 1.40 & 7.25 & 5.85 \\
Thailand & 1.96 & 1.24 & 1.94 & 1.49 & 1.60 & -1.19 & 8.49 & 9.68
\end{tabular}

Notes: The tables report some basic statistics for headline inflation and standard core inflation (CPI excluding food and energy). The sample is generally January 1995-June 2018, but core inflation measures follow the sample published in the country's official statistics.

Source: Haver analytics and authors' calculations.

conditional long-term inflation forecast. Formally, $\lim _{j \rightarrow \infty} E\left[\pi_{t+j} \mid I_{t}\right]=\pi_{t}^{*}$, while $\lim _{j \rightarrow \infty} E\left[\pi_{t}-\pi_{t}^{*} \mid I_{t}\right]=0$, where $I_{t}$ denotes the available information at time $t$.

Following Chan et al. (2018), we also incorporate information about long-term inflation expectations into the estimation. The purpose is two-fold. First, long-term inflation expectations are widely acknowledged to exert an important influence on inflation dynamics and provide forward-looking information into the estimation.

The model has time-varying parameters to capture potential changes in the inflation process, and incorporates some features that have been found important in this kind of models, like stochastic volatility, and the modelling of inflation in terms of an inflation gap $\pi_{t}-\pi_{t}^{*}$, that, although stationary, it is allowed to exhibit some persistence. We will refer to our benchmark specification using survey long-term inflation expectations as UCSV-SUR. 
As alternative specification we will also report results from a restricted model specification only using backward-looking information (realized inflation), the UCSV-BL model.

Formally, our benchmark UCSV-SUR model comprises the following set of equations:

$$
\begin{gathered}
\pi_{t}-\pi_{t}^{*}=b_{t}\left(\pi_{t-1}-\pi_{t-1}^{*}\right)+v_{t}, \quad v_{t} \sim N\left(0, e^{h_{v, t}}\right), \\
\pi_{t}^{*}=\pi_{t-1}^{*}+n_{t}, \quad n_{t} \sim N\left(0, e^{b_{n, t}}\right), \\
b_{t}=b_{t-1}+\epsilon_{b, t}, \quad \epsilon_{b, t} \sim T N_{(0,1)}\left(0, \sigma_{b}^{2}\right), \\
S U R_{t}=d_{0, t}+d_{1, t} \pi_{t}^{*}+\epsilon_{z, t}+\psi \epsilon_{z, t-1}, \quad \epsilon_{z, t} \sim N\left(0, \sigma_{w}^{2}\right), \\
d_{i, t}-\mu_{i, t}=\rho_{d_{i}}\left(d_{i, t-1}-\mu_{d_{i}}\right)+\epsilon_{d_{i}, t}, \quad \epsilon_{d_{i}, t} \sim N\left(0, \sigma_{d_{i}}^{2}\right), \quad i=0,1, \\
h_{i, t}=h_{i, t-1}+\eta_{h_{i}}, \quad \eta_{h_{i}} \sim N\left(0, \sigma_{b_{i}}^{2}\right), \quad i=v, n .
\end{gathered}
$$

Equation (1) is a commonly used standard measurement equation that relates current inflation $\pi_{t}$ and trend inflation $\pi_{t}^{*}$ to past inflation and past trend inflation, respectively, expressed in inflation gap form, $\pi_{t}-\pi_{t}^{*}$, as has become standard in the related literature. Observed inflation is therefore decomposed into its trend, which follows a random walk process, and the inflation gap that follows a stationary process with zero mean. $b_{t}$ is a timevarying parameter that measures the evolution of the degree of persistence in the inflation gap. Note that a truncated normal is assumed on the variance of the $b_{t}$ to ensure that $b_{t}<$ $|1|$ is satisfied, so that the inflation gap in equation (1) is stationary at each point of time and the conditional expectation of this process converges to zero as the forecast horizon increases. Formally, $T N_{(0,1)}\left(0, \sigma_{b}^{2}\right)$ denotes the $N(\mu, \sigma)$ distribution truncated to the interval $(0,1)$.Equation $(2)$ is the transition or state equation for trend inflation $\pi_{t}^{*}$.

In the spirit of the UCSV model and a transparent international comparison, our framework does not incorporate additional variables, mainly economic activity, influencing inflation dynamics. While there is some evidence pointing at a very limited contribution of real variables to inflation forecast (e.g. Faust and Wright, 2013), connections between inflation persistence and economic activity (e.g. as incorporated in Morley et al., 2015), may be particularly important in some countries. Our purpose here is to provide novel evidence on trend inflation estimates for Asian economies using an already fairly rich but tractable framework, and leave further extensions of the model for further research.

Equation (4) is fundamental for the main goal of this article, and we provide some additional information on its interpretation here. In the spirit of the standard Mincer-Zarnowitz equation, survey expectations $S U R_{t}$ are linked to the inflation trend $\pi_{t}^{*}$ through a slope coefficient $d_{1, t}$ an intercept $d_{0, t}$. The slope parameter captures the impact of the inflation trend on survey expectations. The intercept $d_{0, t}$ in turn reflects a potential level 'bias' between expected inflation as measured by surveys and trend inflation estimates. Equation (5) is the transition equation for the timevarying parameters $d_{i, t}$. Importantly, since both parameters are allowed to vary over time, our analysis allows for an evaluation of how the relationship between survey expectations and trend inflation has evolved over time. Finally, equation (4) also includes an MA(1) error term to capture changes in survey expectations that may not be fully captured by the persistence in trend inflation.

This model also allows for stochastic volatility within the inflation gap (equation 1) and trend inflation (equation 4) equations, which are modelled as random walk processes. Lastly, all the errors stated above are assumed to be independent over time and among 
them. The UCSV-BL model specification does not include survey expectations, and, equations (4) and (5) would not be part of the estimation.

As standard in the literature, we will focus our discussion on smoothed estimates of trend inflation, which fit better our goal of assessing inflation dynamics and long-term inflation expectations from a historical perspective, but we also report real-time estimates in the country figures below. The model is estimated using Bayesian methods to implement a Markov Chain Monte Carlo algorithm. Precise details on the estimation method are provided in Supplementary Appendix A. In addition, Supplementary Appendix B reports selective evidence on the prior and posterior distributions of all the state variances for the UCSV-SUR, which confirms a clear Bayesian updating from the data for all the posterior distributions.

\section{Inflation in Asia}

Before analysing the insights our empirical framework, we first provide some basis statistics and an overview of Asian inflation developments from a regional perspective.

\subsection{Trend inflation evidence}

Table 2 shows that trend inflation estimates are considerably smoother than actual inflation. This is also reflected in the significant role of transitory (or cyclical) factors in the decomposition of inflation provided in the regional evidence (Fig. 1) and country-specific Figures (see panel A in Figs 3-14). Trend inflation is also smoother than the standard core measures based on the exclusion of the energy and food components. The standard deviation of trend inflation over our sample as a whole is two to five times lower than that of core inflation for most countries (Table 1). It is just broadly similar for Malaysia, and only higher for China, in the latter case reflecting the high levels of inflation in the early part of our sample. By reflecting persistent inflation pressures, the lower volatility of trend inflation estimates is somewhat natural, but it also signals the potential information content of its changes as important signal for forward-looking monetary policy.

\subsection{A regional perspective on inflation developments}

To gauge the presence of some common patterns in inflation developments in Asia, Fig. 1 depicts the median and interquartile ranges for the trend and transitory components of headline inflation across countries, and also investigate the robustness of the main insights for the two subgroups of AEs and EMs in our sample. The bulk of the decline in inflation in the region over the last two decades reflects lower trend inflation. Yet, from a regional perspective, three qualitatively distinct periods can be identified in the decline in trend inflation in the region. There was a gradual, yet very significant, decline in trend inflation between 1995 and 2002, when it halved from almost $4 \%$ to almost $2 \%$. Interestingly both AEs and EMs contributed to the lower trend inflation in the region, although the decline in the former $(3-2 \%)$ was relatively milder than in the latter (from around 6 to $3 \%$ ).

Between 2003 and 2013 the region experienced a second phase characterized by the stability in trend inflation levels, which points to an improvement in the control of inflation in the region, most likely reflecting refinements in monetary policy frameworks and the better anchoring of inflation expectations. Indeed, the magnitude of the transitory shocks to inflation during the period was not lower than before. Interestingly, although Asia may have been relatively less affected by financial market turbulences than other regions, it was similarly impacted by the strong fluctuations in oil and commodity prices in the aftermath of 
Table 2. Trend Inflation in Asia: basic statistics.

\begin{tabular}{lcccccccc}
\hline Trend & Mean & Median & St. deviation & Skewness & Kurtosis & Min. & Max. & Range \\
\hline Australia & 2.85 & 2.65 & 0.53 & 1.07 & -0.21 & 1.96 & 4.10 & 2.14 \\
Hong Kong SAR & 2.48 & 2.35 & 0.46 & 0.64 & -0.43 & 1.77 & 3.65 & 1.88 \\
Japan & 2.44 & 2.34 & 0.47 & 1.06 & 0.98 & 1.71 & 3.91 & 2.21 \\
Korea & 4.99 & 4.45 & 0.96 & 0.91 & -0.57 & 4.06 & 7.13 & 3.07 \\
New Zealand & 0.89 & 0.92 & 0.33 & 0.10 & 2.46 & -0.10 & 1.96 & 2.06 \\
Taiwan POC & 3.06 & 2.58 & 1.47 & 2.14 & 3.52 & 1.57 & 7.64 & 6.07 \\
China & 3.72 & 3.95 & 0.48 & -0.97 & -0.55 & 2.70 & 4.22 & 1.51 \\
India & 1.92 & 1.77 & 0.45 & 1.65 & 1.64 & 1.34 & 3.24 & 1.90 \\
Indonesia & 2.89 & 2.30 & 1.52 & 1.76 & 1.65 & 1.30 & 7.26 & 5.96 \\
Malaysia & 4.92 & 4.53 & 1.12 & 1.66 & 2.07 & 3.93 & 9.02 & 5.09 \\
Philippines & 2.20 & 2.16 & 0.19 & 3.62 & 14.83 & 2.06 & 3.26 & 1.20 \\
Thailand & 1.99 & 2.04 & 0.23 & -0.54 & -0.99 & 1.49 & 2.27 & 0.77 \\
\hline
\end{tabular}

Notes: The table reports some basic statistics for our trend inflation estimates (posterior mean) based on our benchmark model specification (UCSV-SUR, see Section 4 for model details). The sample is January 1995June 2018, to allow for a direct comparison to headline and core inflation measures in Table 1.

Source: Haver analytics and authors' calculations.

the GFC, as the sharp decline into negative territory in the transitory inflation component shows. Trend inflation, however, remained broadly unchanged, providing stability to inflation dynamics and allowing for the sharp rebound in inflation rates over 2019.

From 2014 there has been a somewhat more puzzling decline in inflation. Recurrent fluctuations in oil and commodity prices and also food prices, in particular, the declines in 2014-5, triggered a cluster of negative transitory shocks. While the magnitude of those transitory shocks does not seem to be particularly large by historical standards, and clearly smaller than during 2008-9, they lowered headline inflation in the region, in some cases into some long spells of negative inflation rates (Japan, Thailand). Somewhat more surprising was the subtle downward slide in trend inflation. Taken place at already relatively low levels of headline inflation, that decline in trend inflation helps understand the protracted period of below-target inflation in some countries, and the missing pick-up in inflation rates after the rebound in economic activity, particularly since 2017.

Overall, Asian economies have achieved a substantial decline in the level (and volatility) of inflation rates, in line with those of comparable economies since 2010. Yet, there is a significant heterogeneity on inflation experiences in the region: for example, Japan has suffered a protracted period of too low inflation (including deflation), while India has been struggling with relatively high inflation for most of our sample. Importantly, the heterogeneity in Asian inflation experiences cannot be easily reduced to AEs and EMs either. This heterogeneity makes the analysis of Asian inflation experiences challenging, but also very relevant from the perspective of many other countries and regions.

\section{Insights from trend inflation analysis}

Before moving into the individual country experiences, this section provides some evidence on the relative forecast performance of trend inflation compared with core inflation and 
A Trend inflation (All countries)

(Percent)

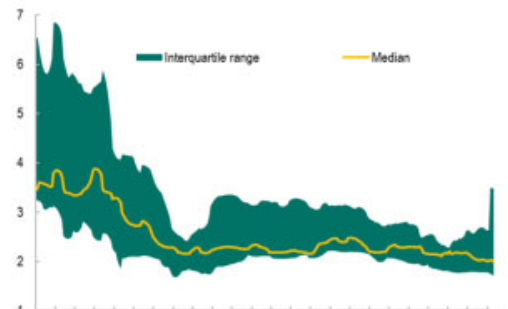

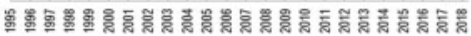

C Trend inflation (Advanced economies) (Percent)

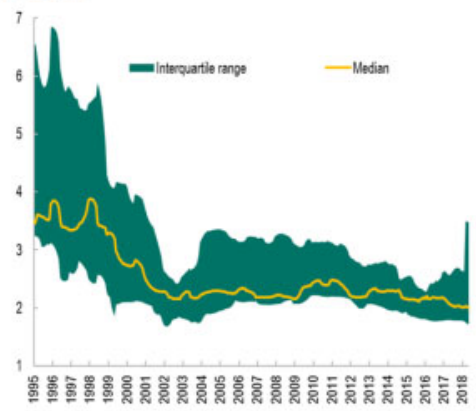

E Trend inflation (Emerging economies) (Percent)

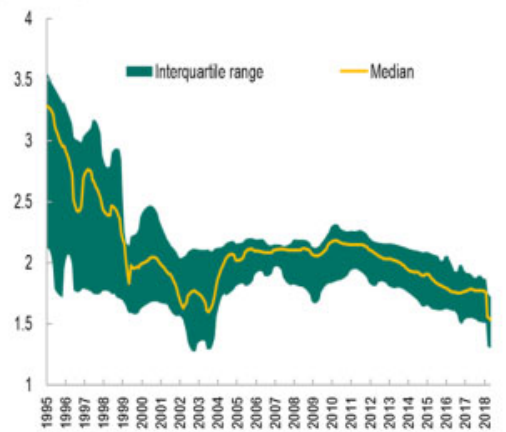

B Transitory inflation (All countries)

(Percent)

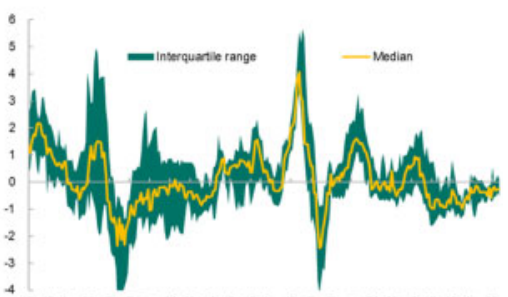

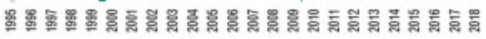

D Transitory inflation (Advanced economies) (Percent)

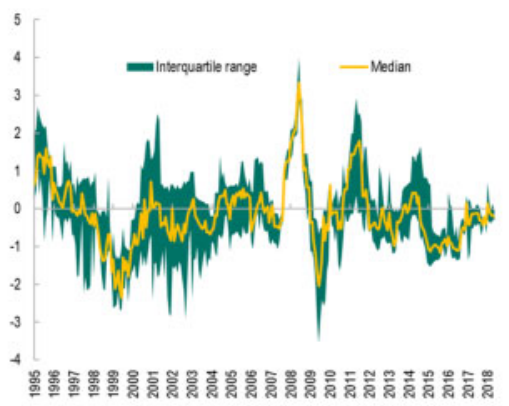

F Transitory inflation (Emerging economies) (Percent)

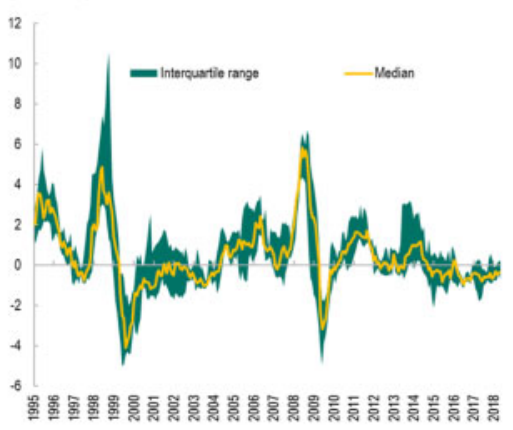

Fig. 1. Asian headline Inflation decomposition. Notes: Analysis of headline inflation dynamics based on our benchmark model specification (UCSV-SUR, see Section 4 for model details). The panel shows the median (solid yellow line) and the interquartile range of trend and transitory inflation components (green shadowed area) for 12 Asian economies, six advanced (Australia, New Zealand, Japan, South Korea, Hong Kong SAR, and Taiwan) and six EMs (India, Indonesia, Malaysia, Philippines, Singapore, and Thailand). Source: Haver analytics and authors' calculations.

surveys, and elaborates on how trend inflation helps to analyse developments in long-term inflation expectations. 


\subsection{Forecast performance}

Relative forecast performance has been an important element of the debate on alternative measures of underlying inflation. Even at an individual country level, assessing the forecast capabilities of alternative underlying inflation measures often requires making some relatively arbitrary choices over indicators and samples (see, e.g. Rich and Steindel, 2007). Indeed, a comprehensive assessment of the forecast properties of any underlying inflation measure could benefit from a multivariate setting in which a potentially different set of additional variables are selected for each country. Given the heterogeneity of inflation experiences and monetary policy regimes in our country sample, such an analysis is beyond the scope of this article. Table 3, however, presents some illustrative evidence based on the root mean square forecast error (RMSFE):

$$
\text { RMSFE }=\sqrt{\frac{1}{N}\left(\sum_{i=1}^{N} e_{i}^{2}\right)}
$$

where $e_{i}$ is the forecast error, defined as the observed inflation rates less the underlying inflation measure. Specifically, we consider forecast performance at two different horizons, 2 and 5 years ahead, to focus respectively on the comparisons to core inflation and survey long-term expectations (Consensus Economics long-term forecasts for headline inflation), and over both the full sample 1995-2018 and the post-GFC period 2010-8. ${ }^{4}$ Moreover, we report RMSFEs for our trend inflation estimates (mean posterior) both estimated in (pseudo) real-time and smoothed over the full sample.

At the 2-year horizon, for all countries but Indonesia, the RMSFEs of (smoothed) trend inflation estimates are lower than those for the official core inflation measures over our sample as a whole. ${ }^{5}$ Since the performance of underlying inflation measures is likely to be influenced by the specific sample under consideration, and the forecast performance of underlying inflation measures has been often found to vary over time, we also consider a more recent post-GFC subsample. Over 2010-8, trend inflation estimates have outperformed standard core measures in most countries, with the exception of India and New Zealand (marginally), but, in contrast to the full sample evidence, including Indonesia. Moreover, that broadly holds for real-time trend estimates as well, which, although displaying somewhat higher RMSFEs than their smoothed versions for most countries, beat core measures in the majority of countries.

At the 5-year horizon (smoothed) trend inflation measures tend to display lower RMSFEs than survey (long-term) forecasts in most countries (all but Japan and very marginally for Indonesia). Over the post-GFC sample, smoothed and real-time estimates of trend inflation outperformed survey measures for most countries, with Japan, India, and Indonesia being the exceptions. Interestingly, however, both smoothed and real-time trend inflation estimates display in the majority of cases lower RMSFEs than core inflation at long horizons (apart from Indonesia), while survey forecasts fail to do so for many countries.

4 Results at other horizons are qualitatively similar in most countries in our sample.

5 In our full sample calculations, we restrict our comparison to the periods in which official core measures have been published in each country (see, e.g. Haver and National Statistial Institutes for the specific periods). 


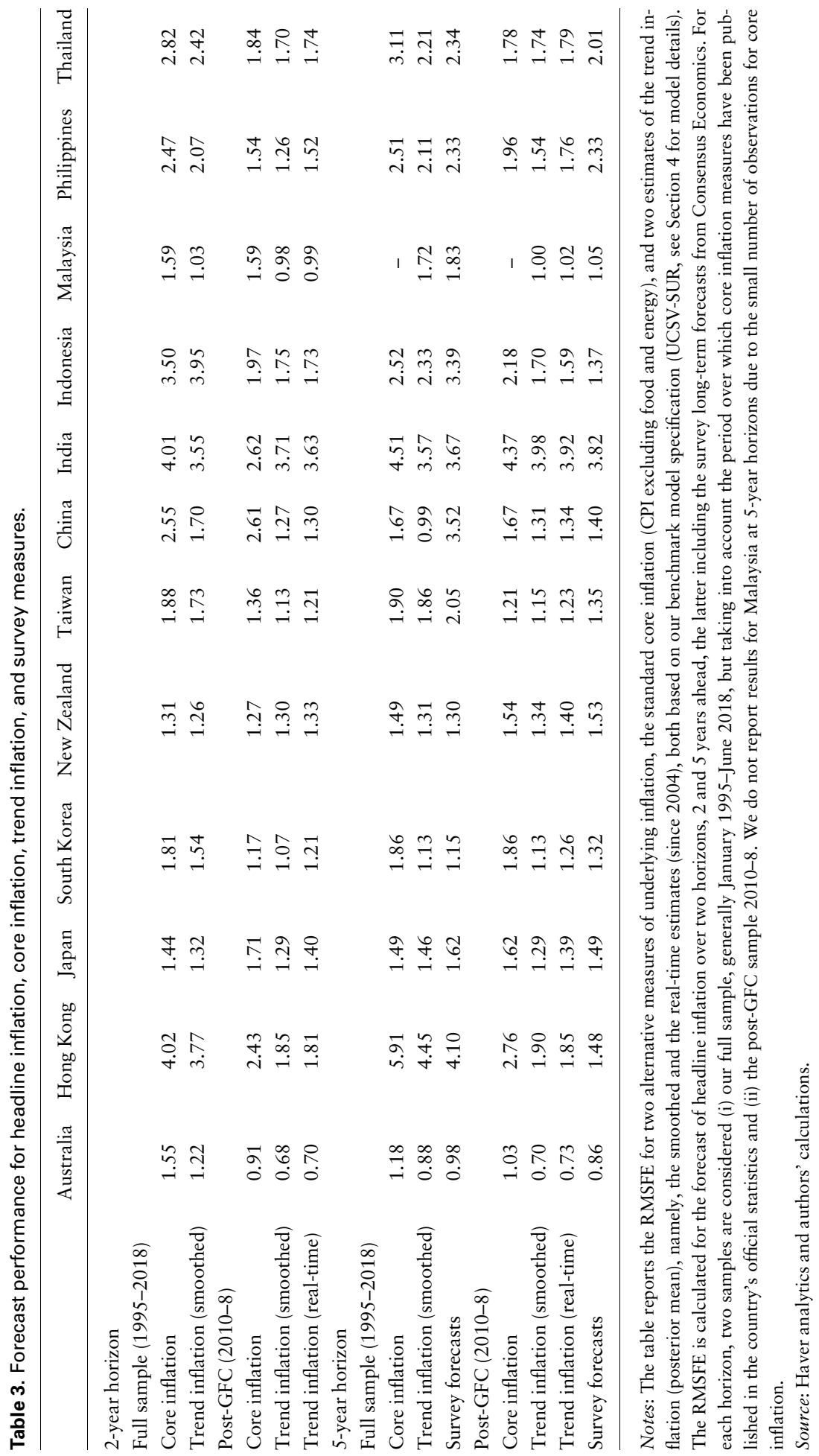




\subsection{Contributions from trend inflation modelling}

To better understand how trend inflation estimation helps inform inflation analysis and the assessment of survey long-term inflation expectations in each country, this section discusses several pieces of evidence that will be reported in Figs 3-14 in the next section. First, by decomposing observed inflation into its trend and transitory components (based on our UCSV-SUR model) we can discuss the extent to which the low-inflation rates experienced in many Asian countries since 2014 were mainly transitory, or may point to a lasting period of low inflationary pressures.

Secondly, we use our trend inflation estimates to interpret developments in survey longterm inflation expectations. While widely monitored by central banks to gauge their credibility, most of the analysis is based on the level (compared with the inflation target) and volatility of long-term inflation expectations (e.g. IMF, 2018b). By providing evidence on the level of inflation that should be expected to prevail once transitory influences die away, trend inflation estimates can provide very valuable information for central banks, not only for assessing the likelihood of hitting the target in the future, but also to interpret changes in survey expectations, which is particularly relevant since the GFC. Despite extended periods of below-target inflation in several AEs, survey long-term inflation expectations remained relatively unchanged with respect to the pre-GFC levels in many countries. That evidence has raised concerns that survey inflation expectations may have become too disconnected from actual inflation developments as in the USA (Chan et al., 2018), the euro area (Garcia and Poon, 2018), and even earlier for Japan (Fuhrer et al., 2012).

Recent literature has emphasized rigidities in expectation formation arising due to sticky information (i.e. information sets only updated infrequently), or information processing frictions due to noisy information, either because true values are observed with some error, or because there is some rational inattention (see Coibion et al. (2018) for a detailed discussion and references). ${ }^{6}$ Our analysis shows that trend inflation estimates help assessing developments in survey expectations also at long-term horizons, while most literature has predominantly focused on shorter horizons, and provides new international evidence for the literature on expectation formation.

Specifically, a key prediction of theoretical models incorporating rigidities in expectation formation models is that expectations will under-respond following a shock relative to the response of the macroeconomic variable (Coibion and Gorodnichenko, 2012). ${ }^{7}$ For example, if a shock lowers inflation, in the presence of informational rigidities, inflation forecasts are likely to underestimate the decline of inflation for a number of periods. Our evidence suggests that in most cases survey expectations have tracked major historical patterns in inflation quite well, in particular, the significant moderation in inflation in the region we documented in Section 5.2. However, in the late 2010s some countries have experienced not only protracted periods of low and below-target inflation but also significant declines in trend inflation, which point to persistently lower pressures on inflation that have not been well captured by surveys in all cases.

We will elaborate on insights from trend inflation estimates when reviewing individual country experiences to draw conclusions on the evolution of central bank credibility, the

6 Bounded rationality and (adaptive) learning models are other possible departures from full rationality.

7 Mertens and Nason (2020) also shows that stickiness in (USA) survey inflation forecasts is not invariant to the inflation process. 
strength of the expectation channel on inflation dynamics, and the information content of survey long-term inflation expectations for each country. To that end, Figs 3-14 (panel B) report the trend inflation estimates for two model specifications, our benchmark specification UCSV-SUR (both smoothed and real-time estimates), the restricted backward-looking (UCSV-BL) model, and survey expectations.

In addition, the volatility of the shocks to both the trend and the inflation gap (Figs 314, panels $\mathrm{C}$ and $\mathrm{D}$ ) provides important evidence of the drivers of the key inflation components and how they have varied over time. The decline not only in the average level but also the volatility of headline inflation in most countries points to an important improvement in the control of inflation in the region. Shocks to the persistent components of inflation can also help to assess the extent of such an improvement. Indeed, the volatility of shocks to trend inflation has also tended to decline over time in most countries. We further explore the extent of that improvement by calculating the contribution of trend inflation shocks to overall inflation volatility (Fig. 2). In most countries there is a lower contribution of trend inflation shocks over time, with the decline taking place either gradually (China, Hong Kong SAR, and Taiwan) or amid some temporary spikes (Japan, Malaysia, and Indonesia). But that evidence also unveils some noticeable experiences towards the end of our sample. For example, shocks to trend inflation, although limited, had an increasing role in overall inflation volatility among some of the countries experiencing relatively low (and below target) inflation levels (e.g. Thailand, Australia, New Zealand, and to a lesser extent South Korea). Interestingly, these time-varying evidence suggests that different propagation mechanisms may be at play under a low inflation environment, ${ }^{8}$ which may call for moving beyond a basic distinction between AEs and EMs and consider the country-specific situation to better understand inflation dynamics and trends.

Finally, we focus on the model-based evidence that is more relevant for monetary policy and for a comparison across countries. We will not report systematically on other model estimation results, and, for example, restrict explicit references to changes over time in the persistence of transitory inflation influences-measured by the parameter $b_{t}$ in our modelor the two metrics governing the time-varying differences between survey measures and trend inflation estimates-the slope coefficient $d_{1, t}$ and the intercept $d_{0, t}$ in equation (4)to those cases in which they are important to fully understand the insights for a specific country (Garcia and Poon (2021) offer a more detailed discussion and additional evidence for the euro area and the USA).

\section{Country experiences}

This section reviews individual country experiences, mainly in the 2010s. Although our framework does not focus on common shocks, our results suggest that relatively similar transitory shocks have hit their inflation rates over the 2010s (Figs 3-14A, panel A), while

8 For example, Okuda et al. (2019) uses sector-level surveys for Japanese firms to unveil a negative relationship between the degree of demand shock heterogeneity and the sensitivity of inflation to real activity since the late 1990s, while L'Huillier and Zame (2014) argue that price stickiness can arise endogenously under stronger anchoring of inflation expectations leading to a flattening of the Phillips Curve that may compromise the central bank objective of economic stabilization. 

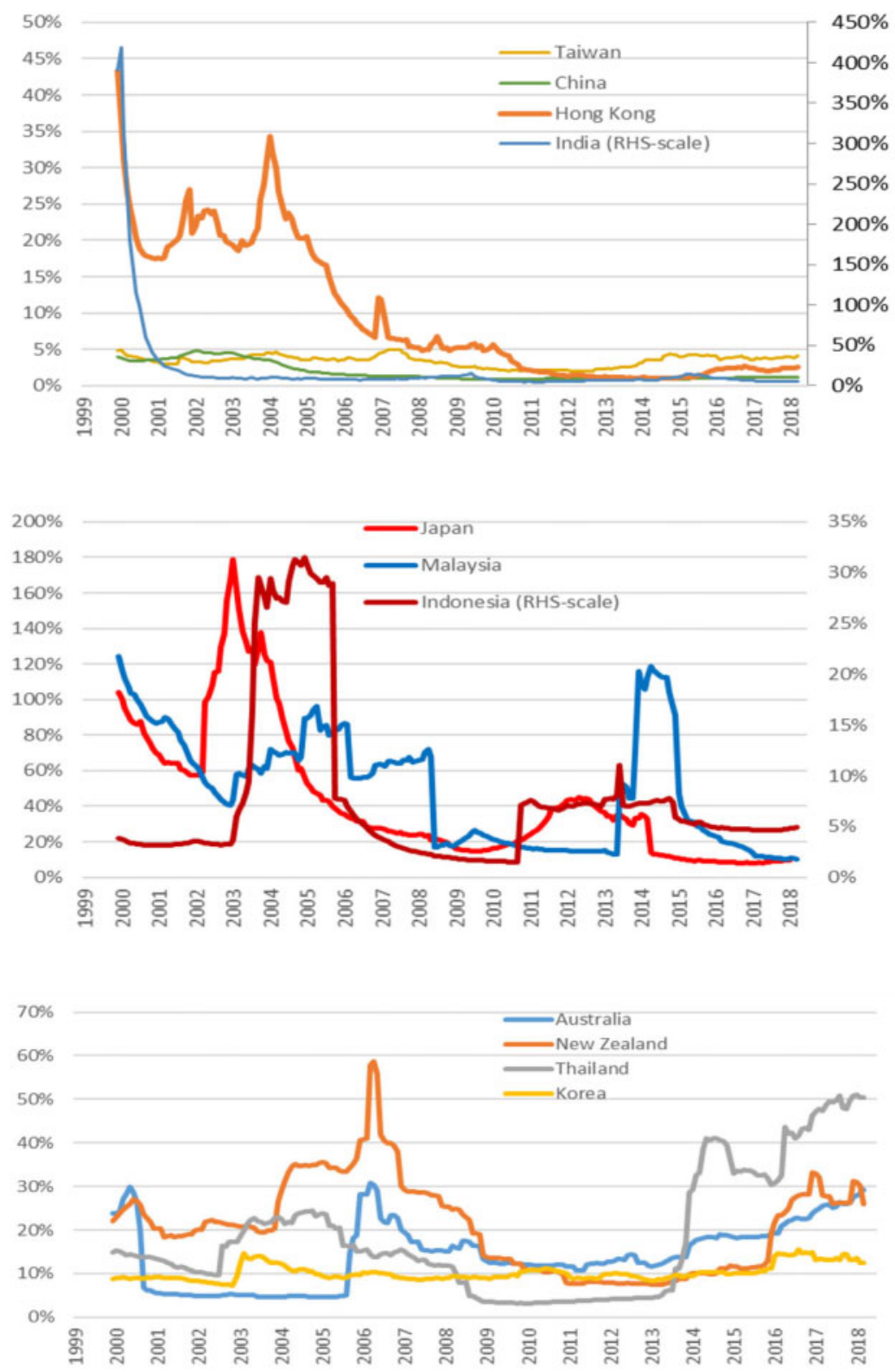

Fig. 2. Contribution of shocks to trend inflation to headline inflation volatility (percent). Notes: the charts depict the contribution of shocks to trend inflation based on our benchmark model specification (UCSV-SUR, see Section 4 for model details) to the volatility of headline inflation using a 5-year window for eleven Asian economies, six advanced (Australia, New Zealand, Japan, South Korea, Hong Kong SAR and Taiwan) and five EMs (India, Indonesia, Malaysia, Singapore, and Thailand). Source: Haver analytics and authors' calculations. 
A Headline inflation decomposition: trend and transitory components (Percent)

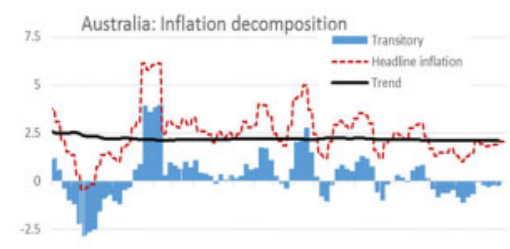

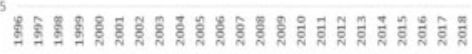

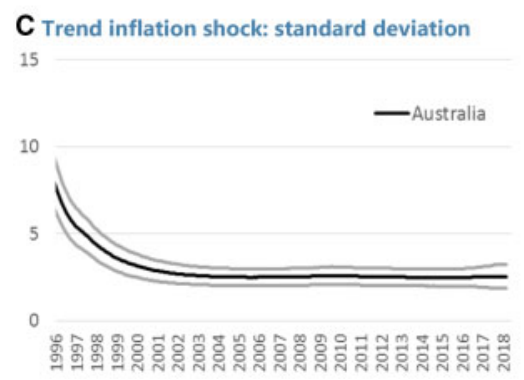

\section{B Trend inflation (Percent)}

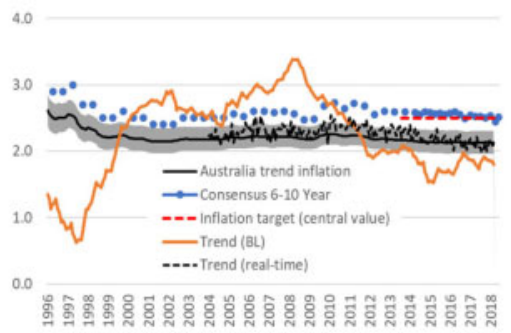

D Inflation gap shocks: standard deviation 15

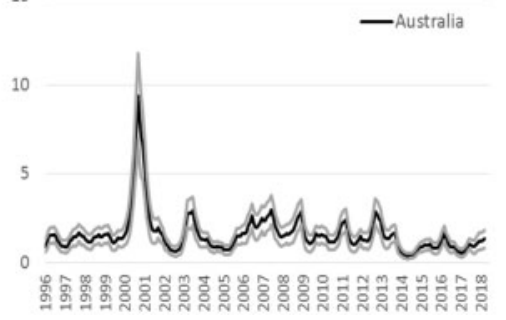

Fig. 3. Inflation analysis: Australia. Notes: analysis of headline inflation dynamics based on our benchmark model specification (UCSV-SUR, see Section 4 for model details). Panel A reports the decomposition of inflation into a trend (or persistent) component and the transitory (or inflation gap) component. Panel B also includes two trend inflation estimates based on the benchmark model specification, the smoothed estimates (solid black line, with shadowed area reflecting 16th and 84th quantiles), and the real-time estimates (from 2004, black discontinued line), trend inflation estimates using an alternative model (UCSV-BL, orange line) using only backward-looking information (historical inflation realizations), the level of the inflation target (or central value of the target range, red dashed line) announced by the central bank, and survey (long-term) inflation expectations from Consensus Forecasts (blue dots). Panels $\mathrm{C}$ and $\mathrm{D}$ show the estimated standard deviation of the volatility of inflation gap and trend inflation respectively, with solid black lines show posterior mean estimates, and the thinner lines and shadowed area show the $66 \%$ confidence sets from the modeĺs posterior distribution. Source: Haver analytics and authors' calculations.

trend inflation may be more driven by domestic forces, including monetary policy (see, e.g. Kamber and Wong, 2020).

Australia and New Zealand exemplify the case of many AEs struggling with low inflation since the GFC. While survey inflation expectations are strongly aligned with the (midpoint) inflation target, trend inflation has been low, which helps understand why inflation outturns have been below-target (Figs 3 and 11). ${ }^{9}$ Indeed, despite a fairly constant magnitude of shocks to trend inflation (see panel C), their relative contribution to overall inflation volatility rose in the last decade (Fig. 2).

9 The strong anchoring of inflation expectations in those two countries explains the significant differences in the trend inflation estimates between the two model specifications, UCSV-SUR and UCSVBL. While the backward-looking model also points to weak inflationary pressures in both countries, incorporating the information content of survey measures of long-term inflation expectations provides much more stable trend inflation estimates. 

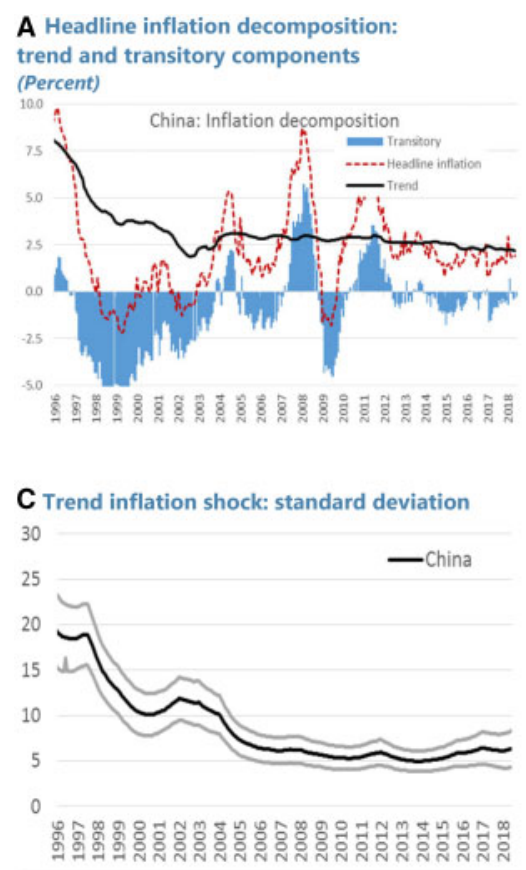

\begin{abstract}
B Trend inflation (Percent)
\end{abstract}

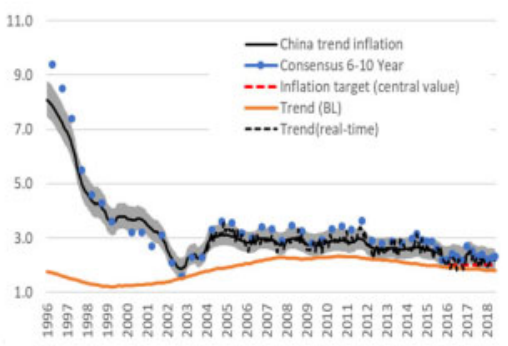

D Inflation gap shocks: standard deviation 30

20

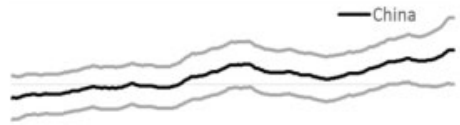

10

0

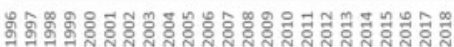

Fig. 4. Inflation analysis: China. Notes: analysis of headline inflation dynamics based on our benchmark model specification (UCSV-SUR, see Section 4 for model details). Panel A reports the decomposition of inflation into a trend (or persistent) component and the transitory (or inflation gap) component. Panel B also includes two trend inflation estimates based on the benchmark model specification, the smoothed estimates (solid black line, with shadowed area reflecting 16th and 84th quantiles), and the real-time estimates (from 2004, black discontinued line), trend inflation estimates using an alternative model (UCSV-BL, orange line) using only backward-looking information (historical inflation realizations), the level of the inflation target (or central value of the target range, red dashed line) announced by the central bank, and survey (long-term) inflation expectations from Consensus Forecasts (blue dots). Panels $\mathrm{C}$ and $\mathrm{D}$ show the estimated standard deviation of the volatility of inflation gap and trend inflation respectively, with solid black lines show posterior mean estimates, and the thinner lines and shadowed area show the $66 \%$ confidence sets from the model's posterior distribution. Source: Haver analytics and authors' calculations.

In our framework, trend inflation persistently below long-term survey expectations leads to the presence of a sizable bias in survey measures. Formally, the $d_{0, t}$ parameter in equation (4) is significantly greater than 0 in statistical sense. The slope parameters $d_{1, t}$ in contrast remain close to their theoretically consistent value of 1 . Given the strong credibility of the Reserve Banks in those two countries, it is likely that such a bias just reflects the power of a (mid-point) target announcement on inflation expectations. But it may also point to some rigidities in expectation formation, and our trend inflation estimates suggest that the central banks should monitor carefully the level of survey inflation expectations, and ensure that a sustained below-target inflation does not trigger a downward revision in their level that could make more difficult a sustained return of inflation back to target.

Differences between trend inflation and surveys may point to more challenging situations for other countries. For example, in Japan actual inflation have run consistently below survey expectations for a considerable period of time (Fig. 7, panel A). Moreover, trend 
A Headline inflation decomposition: trend (RHS scale) and transitory components (Percent)
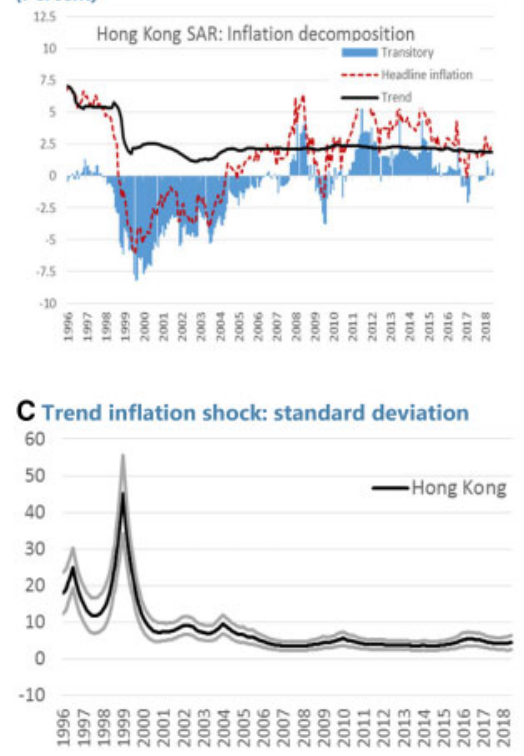

B

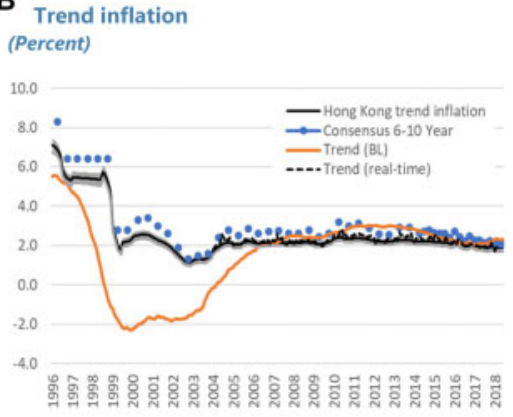

D Inflation gap shocks: standard deviation 20

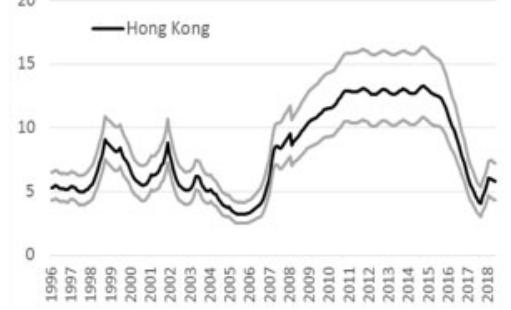

Fig. 5. Inflation analysis: Hong Kong SAR. Notes: Analysis of headline inflation dynamics based on our benchmark model specification (UCSV-SUR, see Section 4 for model details). Panel A reports the decomposition of inflation into a trend (or persistent) component and the transitory (or inflation gap) component. Panel B also includes two trend inflation estimates based on the benchmark model specification, the smoothed estimates (solid black line, with shadowed area reflecting 16th and 84th quantiles), and the real-time estimates (from 2004, black discontinued line), trend inflation estimates using an alternative model (UCSV-BL, orange line) using only backward-looking information (historical inflation realizations), the level of the inflation target (or central value of the target range, red dashed line) announced by the central bank, and survey (long-term) inflation expectations from Consensus Forecasts (blue dots). Panels $C$ and D show the estimated standard deviation of the volatility of inflation gap and trend inflation respectively, with solid black lines show posterior mean estimates, and the thinner lines and shadowed area show the $66 \%$ confidence sets from the modeĺs posterior distribution. Source: Haver analytics and authors' calculations.

inflation estimates have been persistently below the inflation target over the 2010s, particularly since 2013 when the target was raised to $2 \%$, which helps explain the weak inflation rates observed in the country, and also the return to low inflation after the temporary spike in 2014.

South Korea and Thailand have also experienced protracted periods of below-target inflation since the GFC, particularly following the sharp decline in oil prices in 2014-5. In their cases, trend inflation estimates suggest a more protracted disconnection between the inflation target and actual inflation developments, and also between the levels of trend inflation and survey long-term inflation expectations. Indeed, while some of the downward inflationary pressures in those countries were of transitory nature, and similar to those in other countries in the region (Figs 4 and 14, panel A), the declines in trend inflation in Thailand and South Korea show that the downward pressures on inflation had a more persistent nature, and therefore pose a bigger challenge for monetary policy. 
A Headline inflation decomposition: trend and transitory components (Percent)
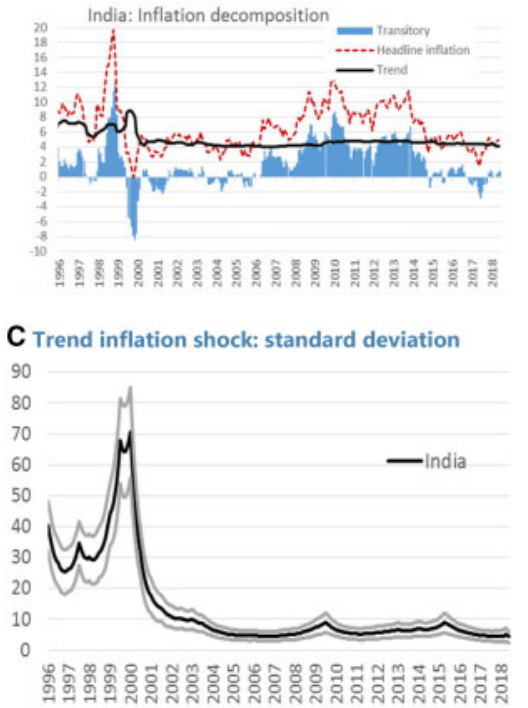
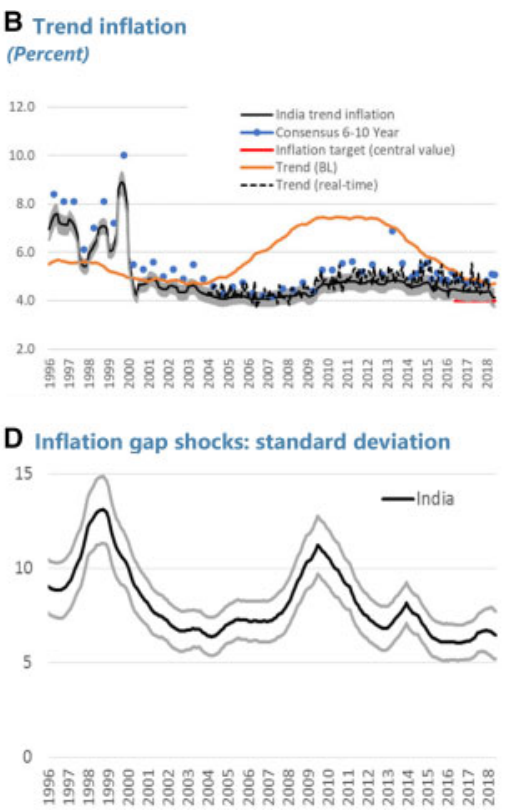

Fig. 6. Inflation analysis: India. Notes: Analysis of headline inflation dynamics based on our benchmark model specification (UCSV-SUR, see Section 4 for model details). Panel A reports the decomposition of inflation into a trend (or persistent) component and the transitory (or inflation gap) component. Panel B also includes two trend inflation estimates based on the benchmark model specification, the smoothed estimates (solid black line, with shadowed area reflecting 16th and 84th quantiles), and the real-time estimates (from 2004, black discontinued line), trend inflation estimates using an alternative model (UCSV-BL, orange line) using only backward-looking information (historical inflation realizations), the level of the inflation target (or central value of the target range, red dashed line) announced by the central bank, and survey (long-term) inflation expectations from Consensus Forecasts (blue dots). Panels $\mathrm{C}$ and $\mathrm{D}$ show the estimated standard deviation of the volatility of inflation gap and trend inflation respectively, with solid black lines show posterior mean estimates, and the thinner lines and shadowed area show the $66 \%$ confidence sets from the models posterior distribution. Source: Haver analytics and authors' calculations.

Headline inflation in South Korea has been sliding downwards over the last two decades, amid a very gradual moderation in growth rates. Yet, since 2012, low inflation became more entrenched, as indicated by the steady downward slides in trend inflation. Long-term survey expectations, also on a downward trend, have run consistently (and in a statistically significant way) above trend inflation estimates most of the time. They were aligned to the announced target of 3\% in the early 2010s, but gradually declined below target since 2013 . With long-term expectations (and trend inflation) already below the previous target of $3 \%$ for several years, the downward revision in the target in 2016 mainly validated those lower inflation expectations. Long-term surveys gradually became more aligned to the new target of $2 \%$ over time, but a tendency to decline below that level persists.

Developments in trend inflation offer some insights to understand those changes in survey expectations. The below-target (around $2.25 \%$ ) and declining trend inflation over the period 2013-6 helps understand the downward revision in survey expectations. The downward revision of the inflation target, however, did not stop the decline in trend inflation 

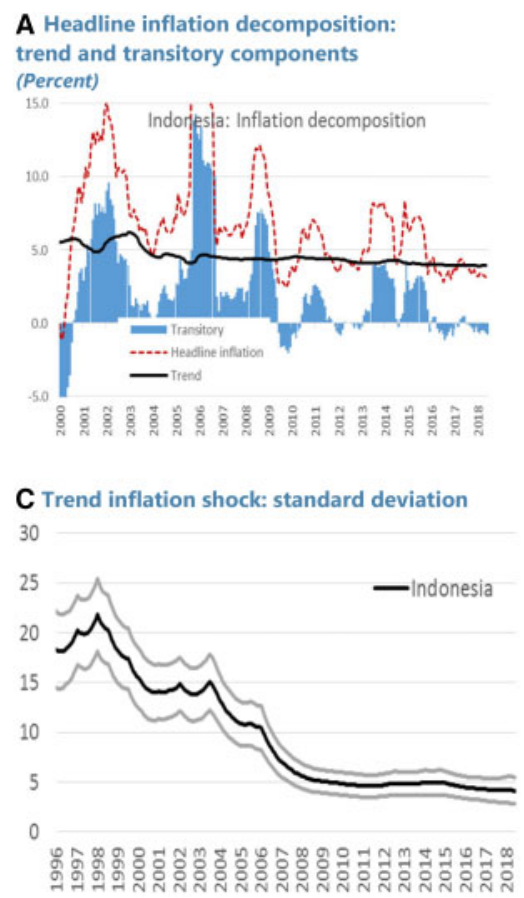
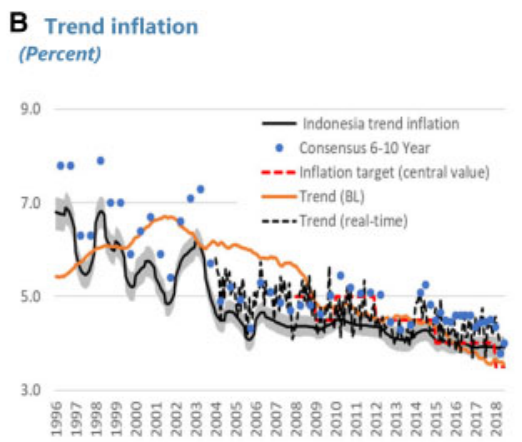

D Inflation gap shocks: standard deviation

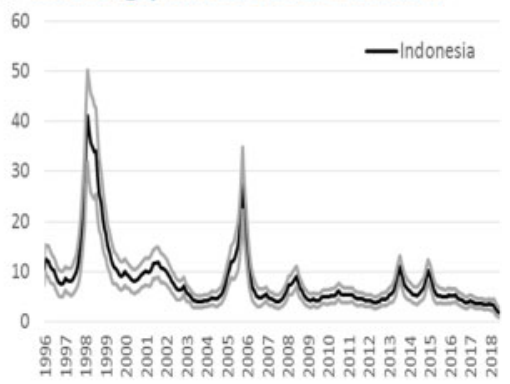

Fig. 7. Inflation analysis: Indonesia. Notes: Analysis of headline inflation dynamics based on our benchmark model specification (UCSV-SUR, see Section 4 for model details). Panel A reports the decomposition of inflation into a trend (or persistent) component and the transitory (or inflation gap) component. Panel B also includes two trend inflation estimates based on the benchmark model specification, the smoothed estimates (solid black line, with shadowed area reflecting 16th and 84th quantiles), and the real-time estimates (from 2004, black discontinued line), trend inflation estimates using an alternative model (UCSV-BL, orange line) using only backward-looking information (historical inflation realizations), the level of the inflation target (or central value of the target range, red dashed line) announced by the central bank, and survey (long-term) inflation expectations from Consensus Forecasts (blue dots). Panels $\mathrm{C}$ and $\mathrm{D}$ show the estimated standard deviation of the volatility of inflation gap and trend inflation respectively, with solid black lines show posterior mean estimates, and the thinner lines and shadowed area show the $66 \%$ confidence sets from the models posterior distribution. Source: Haver analytics and authors' calculations.

pointing to a continuation of subdued inflation pressures. From 2017 onwards, survey expectations have been revised further downwards, towards levels slightly below the $2 \%$ target and become closer to the trend inflation level, which would be consistent with the presence of some temporary rigidities in expectation formation. That evidence suggests that modelling a time-varying relationship between survey long-term inflation expectations and trend inflation can help central banks better interpret and, in some circumstances, even to anticipate movements in survey expectations.

In the case of Thailand, the period of below-target inflation is restricted to the last part of our sample. This is quite noticeable because, despite somewhat volatile survey long-term inflation expectations over a sample as whole, Thailand was a very successful inflation targeter among EMs, with headline inflation quite stable in the 3-5\% range since the AFC. While remaining significantly below survey measures, trend inflation was broadly stable 

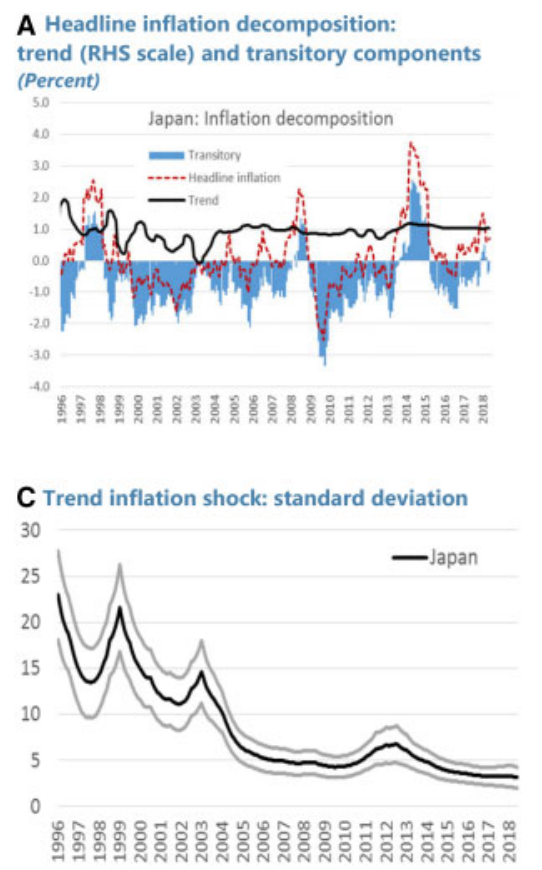

\section{B Trend inflation (Percent)}

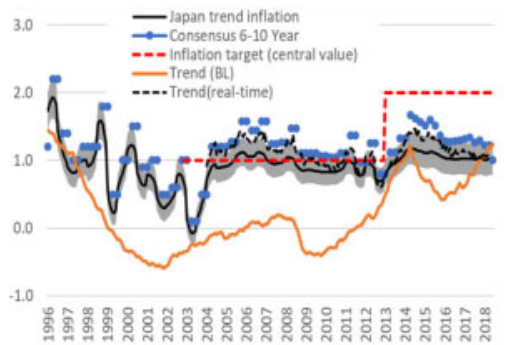

D Inflation gap shocks: standard deviation

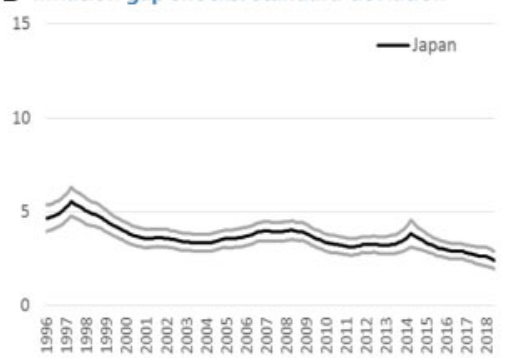

Fig. 8. Inflation analysis: Japan. Notes: Analysis of headline inflation dynamics based on our benchmark model specification (UCSV-SUR, see Section 4 for model details). Panel A reports the decomposition of inflation into a trend (or persistent) component and the transitory (or inflation gap) component. Panel B also includes two trend inflation estimates based on the benchmark model specification, the smoothed estimates (solid black line, with shadowed area reflecting 16th and 84th quantiles), and the real-time estimates (from 2004, black discontinued line), trend inflation estimates using an alternative model (UCSV-BL, orange line) using only backward-looking information (historical inflation realizations), the level of the inflation target (or central value of the target range, red dashed line) announced by the central bank, and survey (long-term) inflation expectations from Consensus Forecasts (blue dots). Panels $\mathrm{C}$ and $\mathrm{D}$ show the estimated standard deviation of the volatility of inflation gap and trend inflation respectively, with solid black lines show posterior mean estimates, and the thinner lines and shadowed area show the $66 \%$ confidence sets from the models posterior distribution. Source: Haver analytics and authors' calculations.

around $2.5 \%$ between 2003 and 2015. The announcement of an explicit target band for headline inflation $(2.5 \pm 1.5 \%)$ at the end of 2015 , however, coincided with the significant downward pressures on inflation stemming from the sharp decline in oil prices. While part of those pressures were of transitory nature (see Fig. 14A), and quantitatively similar to those in other countries in the region, the gradual decline in trend inflation, which intensified since 2016 becoming significantly-both in statistical and economic sense-below the (mid-point) inflation target, has also been pointing to the presence of rather persistent disinflationary pressures. Inflation remained in negative territory for 15 consecutive months between 2014 and 2016, and has been below the mid-point (and even outside the target band) for long periods since then. Indeed, the UCSV-BL model point to some of the strongest disinflationary pressures in the region as a whole. Moreover, despite only a mild increase in the magnitude of shocks to trend inflation (see Fig. 14C) their relative contribution to overall inflation volatility rose in the last decade. 

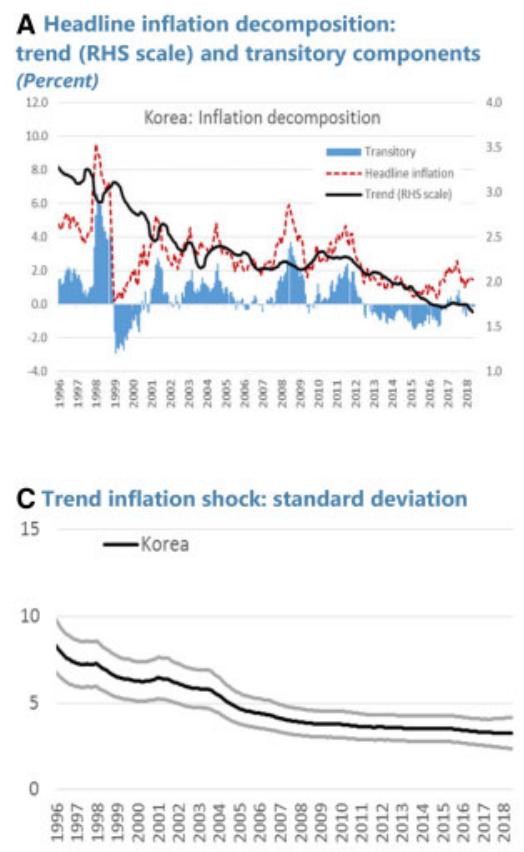
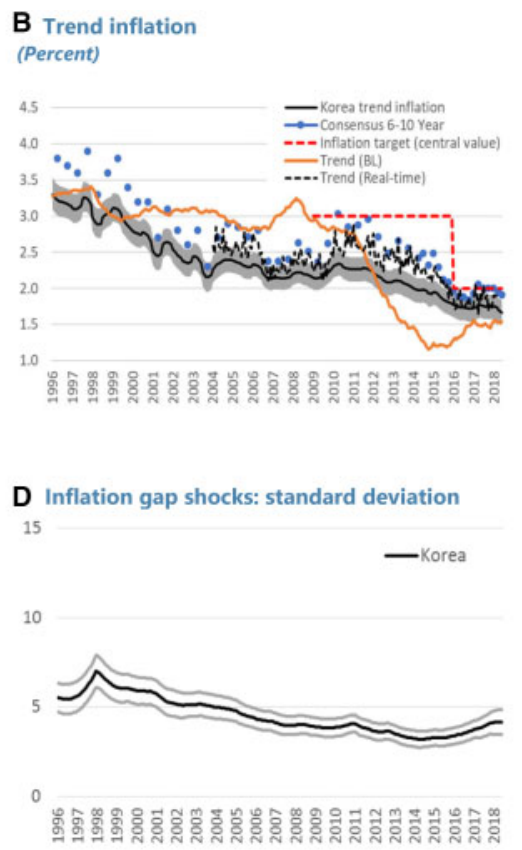

Fig. 9. Inflation analysis: South Korea. Notes: Analysis of headline inflation dynamics based on our benchmark model specification (UCSV-SUR, see Section 4 for model details). Panel A reports the decomposition of inflation into a trend (or persistent) component and the transitory (or inflation gap) component. Panel B also includes two trend inflation estimates based on the benchmark model specification, the smoothed estimates (solid black line, with shadowed area reflecting 16th and 84th quantiles), and the real-time estimates (from 2004, black discontinued line), trend inflation estimates using an alternative model (UCSV-BL, orange line) using only backward-looking information (historical inflation realizations), the level of the inflation target (or central value of the target range, red dashed line) announced by the central bank, and survey (long-term) inflation expectations from Consensus Forecasts (blue dots). Panels $\mathrm{C}$ and $\mathrm{D}$ show the estimated standard deviation of the volatility of inflation gap and trend inflation respectively, with solid black lines show posterior mean estimates, and the thinner lines and shadowed area show the $66 \%$ confidence sets from the model's posterior distribution. Source: Haver analytics and authors' calculations.

Against this background, survey inflation expectations were also revised downwards, after remaining even above the mid-point inflation target (and trend inflation) until 2017. Thailand's low inflation experience also provides strong evidence in support of the usefulness of trend inflation estimates to interpret underlying inflationary pressures, and to complement the information from survey measures of long-term inflation expectations, particularly when there may be signals of some rigidities in expectation formation leading to an eventual de-anchoring of inflation expectations. Moreover, Thailand is one of the few countries in our sample in which the persistence of the inflation gap-measured by the parameter $b_{t}$ in equation (1)-has experienced a slight increase towards around 0.5 , a value in the upper part of the distribution of estimates among the countries in our sample, which also contributes to explain the persistence of low inflation in the country.

Indonesia, in contrast, has struggled to align private sector expectations with the gradual revision in the (mid-point) inflation target since 2015 (see Fig. 6). Importantly, 

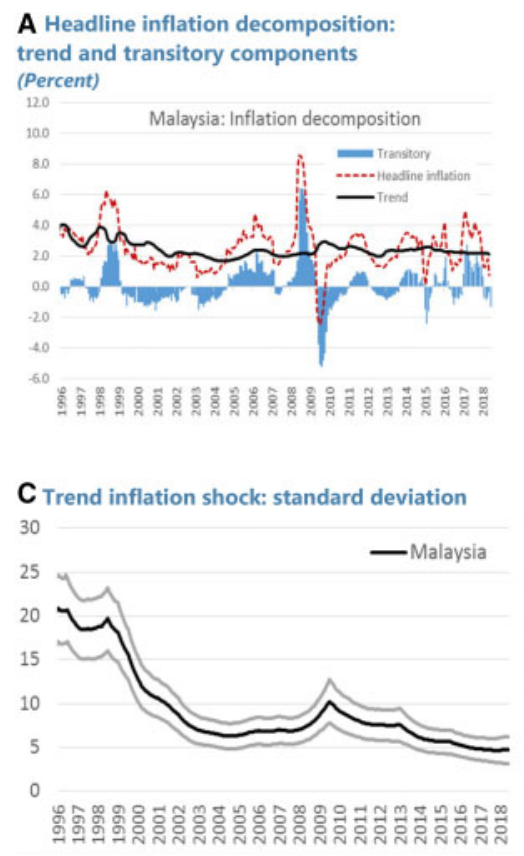
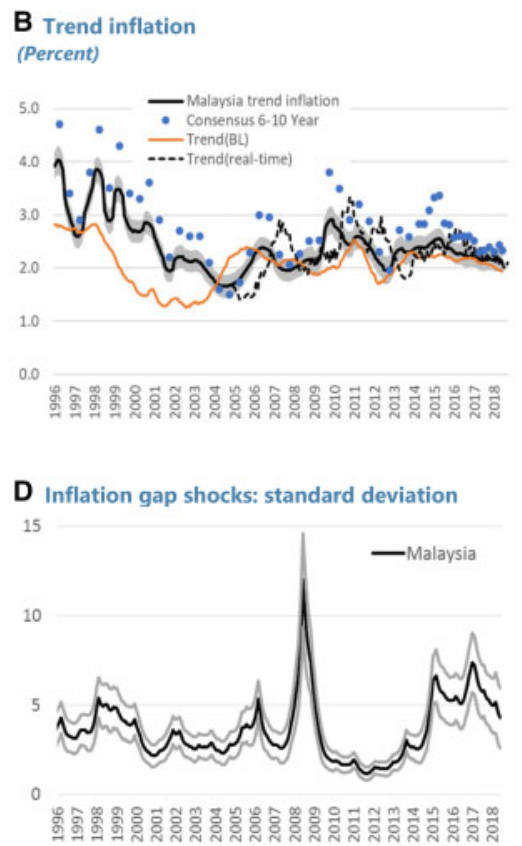

Fig. 10. Inflation analysis: Malaysia. Notes: Analysis of headline inflation dynamics based on our benchmark model specification (UCSV-SUR, see Section 4 for model details). Panel A reports the decomposition of inflation into a trend (or persistent) component and the transitory (or inflation gap) component. Panel B also includes two trend inflation estimates based on the benchmark model specification, the smoothed estimates (solid black line, with shadowed area reflecting 16th and 84th quantiles), and the real-time estimates (from 2004, black discontinued line), trend inflation estimates using an alternative model (UCSV-BL, orange line) using only backward-looking information (historical inflation realizations), the level of the inflation target (or central value of the target range, red dashed line) announced by the central bank, and survey (long-term) inflation expectations from Consensus Forecasts (blue dots). Panels $\mathrm{C}$ and $\mathrm{D}$ show the estimated standard deviation of the volatility of inflation gap and trend inflation respectively, with solid black lines show posterior mean estimates, and the thinner lines and shadowed area show the $66 \%$ confidence sets from the models posterior distribution. Source: Haver analytics and authors' calculations.

however, the fact that trend inflation remained more aligned to the inflation target, and significantly below the survey measures, pointed to actual inflation realizations turning out in line with the target, and also help understand the downward revision of long-term survey expectations towards the end of the sample.

Other Asian countries also offer interesting insights for other countries based on their particular inflation experiences. India, for example, had been struggling with episodes of relatively high inflation and supply shocks. With more formal inflation targeting since June 2016 with price stability—a target band $(4.0 \pm 2 \%)$ —as primary objective for monetary policy, the Reserve Bank of India managed to keep inflation at fairly low levels by historical standards. Despite somewhat volatile (and above target) survey inflation expectations, the trend inflation estimates based on our benchmark model have been fairly stable, and broadly consistent with the definition of price stability, attributing the high headline inflation between 2009 and 2014 mainly to a series of transitory shocks. Interestingly, there is a 
A Headline inflation decomposition: trend and transitory components (Percent)

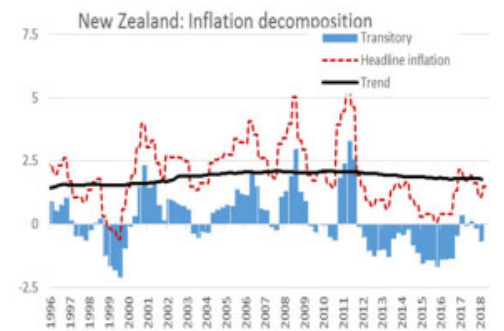

\section{Trend inflation shock: standard deviation} 15

10

5

0

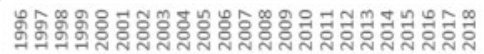

B Trend inflation (Percent)

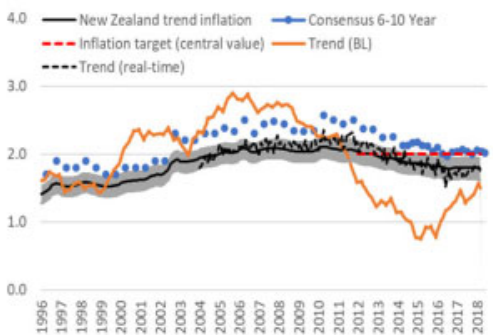

D Inflation gap shocks: standard deviation 15 - New Zealand

10

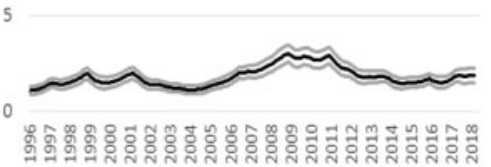

Fig. 11. Inflation analysis: New Zealand. Notes: Analysis of headline inflation dynamics based on our benchmark model specification (UCSV-SUR, see Section 4 for model details). Panel A reports the decomposition of inflation into a trend (or persistent) component and the transitory (or inflation gap) component. Panel B also includes two trend inflation estimates based on the benchmark model specification, the smoothed estimates (solid black line, with shadowed area reflecting 16th and 84th quantiles), and the real-time estimates (from 2004, black discontinued line), trend inflation estimates using an alternative model (UCSV-BL, orange line) using only backward-looking information (historical inflation realizations), the level of the inflation target (or central value of the target range, red dashed line) announced by the central bank, and survey (long-term) inflation expectations from Consensus Forecasts (blue dots). Panels $\mathrm{C}$ and $\mathrm{D}$ show the estimated standard deviation of the volatility of inflation gap and trend inflation respectively, with solid black lines show posterior mean estimates, and the thinner lines and shadowed area show the $66 \%$ confidence sets from the models posterior distribution. Source: Haver analytics and authors' calculations.

significant difference between trend inflation estimates from our benchmark specification and from the purely backward-looking estimation (UCSV-BL). The latter, in the absence of additional information, tends to track too closely actual inflation realizations, and is particularly striking in the case of India. Looking ahead, to the extent that the level and volatility of trend inflation shocks remain fairly stable, further convergence of trend and survey expectations to the official inflation target should be expected.

Malaysia also offers an interesting example of fairly stable inflation since the 2000s without adopting a formal inflation targeting framework. Indeed, our trend inflation estimates have fluctuated within a narrow band of $2-3 \%$ over most of our sample since the early 2000s, despite fairly volatile survey inflation expectations, and the size of the transitory component of headline inflation is also comparable to that of similar countries. Through gradual improvements in the monetary policy framework including exchange rate management (see, e.g. Dany-Knedlik and Garcia, 2018), Bank Negara Malaysia has 

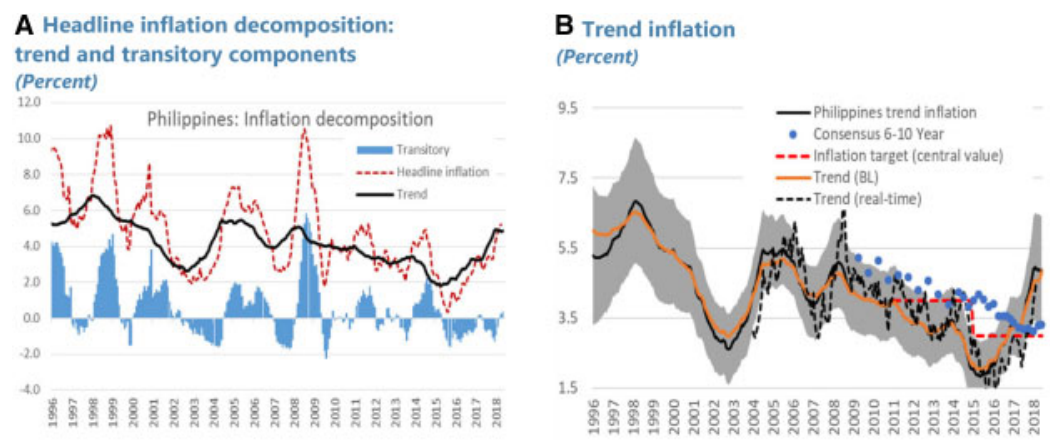

Fig. 12. Inflation analysis: Philippines. Notes: Given the limited availability of long-term survey measures of inflation expectations (see panel B, blue dots), trend inflation estimates for the Philippines are based on Chan et al. (2013). Such model specification does not allow for stochastic volatility in the trend inflation estimates, and therefore the volatility of its shocks is not reported here, in contrast to the rest of the country panels in our sample. Panel A reports the decomposition of inflation into a trend (or persistent) component and the transitory (or inflation gap) component. Panel B also includes trend inflation estimates (solid black line, with shadowed area reflecting 16th and 84th quantiles), the realtime estimates (from 2004, black discontinued line), trend inflation estimates using an alternative model (UCSV-BL, orange line) using only backward-looking information (historical inflation realizations), the level of the inflation target (or central value of the target range, red dashed line) announced by the central bank, and survey (long-term) inflation expectations from Consensus Forecasts (blue dots). Source: Haver analytics and authors' calculations.

delivered fairly stable inflation and supported economic activity in the country. Interestingly, the lack of an explicit inflation target may be however behind the significant volatility of survey measures of inflation expectations, and, in turn, help explain why in this case UCSV-SUR and UCSV-BL models offer very similar trend inflation estimation results.

China, Taiwan, and Hong Kong have experienced quite stable inflation rates lately despite facing transitory inflation pressures of similar magnitude to other countries in the region (see Figs 4, 5, and 13), which, compared with the fairly high levels early in our sample, seems to reflect that the improvement in their monetary policy frameworks has translated into sound stability in inflation rates and inflation expectations for most of the 2010s. Interestingly, as for Malaysia, the experiences in these countries also highlight the usefulness of exchange rate management to control inflation trends as alternative monetary policy strategy to formal inflation targeting. In addition, survey inflation expectations also appear to be very much aligned with trend inflation estimates over recent years.

The Philippines is one of the few countries in the region which has experienced fairly high inflation rates in the 2010s. While the country has experienced high-inflation episodes in the past, the sharp rise in inflation following the rebound in oil prices over 2018 was somewhat unique in the region. The estimation of trend inflation for The Philippines within our framework faces some special challenges, since survey long-term inflation expectations are only available since 2009. That helps explain why estimates are relatively similar both for our benchmark specification and for the purely backward-looking model, and also surrounded by higher uncertainty than for other countries. This being said, trend inflation estimates have been more volatile than for peer countries, and have moved from well below the inflation target in 2015-6 to well above it in 2018 . 
A Headline inflation decomposition: trend (RHS scale) and transitory components (Percent)
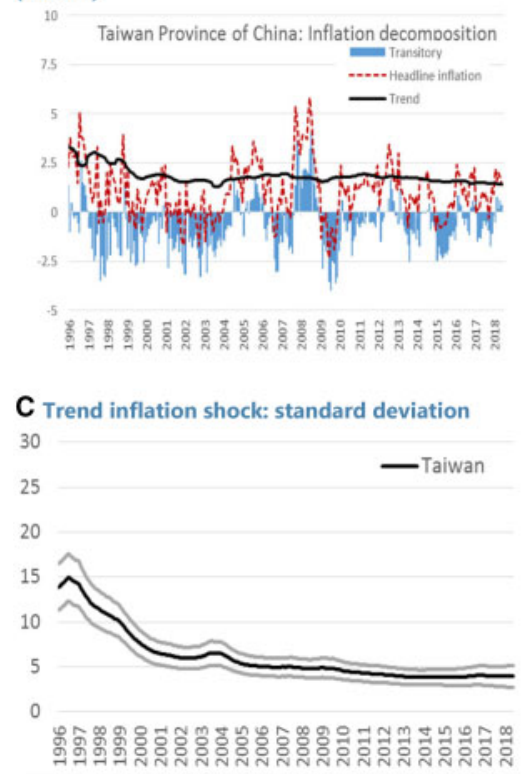

\section{B Trend inflation (Percent)}

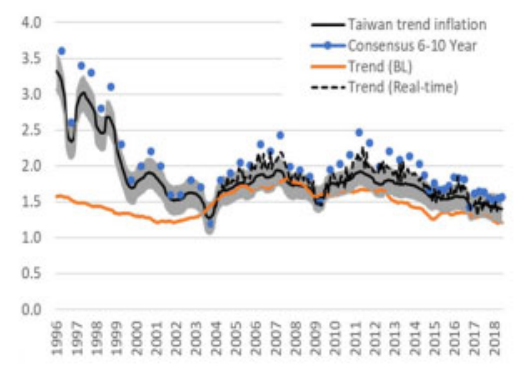

D Inflation gap shocks: standard deviation 15

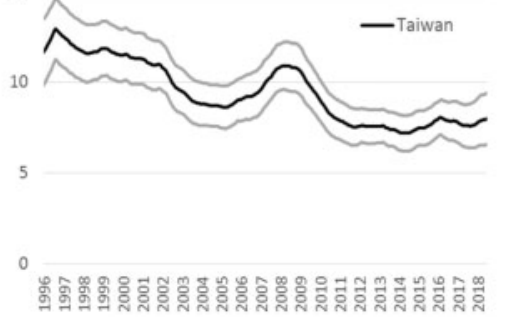

Fig. 13. Inflation analysis: Taiwan. Notes: analysis of headline inflation dynamics based on our benchmark model specification (UCSV-SUR, see Section 4 for model details). Panel A reports the decomposition of inflation into a trend (or persistent) component and the transitory (or inflation gap) component. Panel B also includes two trend inflation estimates based on the benchmark model specification, the smoothed estimates (solid black line, with shadowed area reflecting 16th and 84th quantiles), and the real-time estimates (from 2004, black discontinued line), trend inflation estimates using an alternative model (UCSV-BL, orange line) using only backward-looking information (historical inflation realizations), the level of the inflation target (or central value of the target range, red dashed line) announced by the central bank, and survey (long-term) inflation expectations from Consensus Forecasts (blue dots). Panels $C$ and D show the estimated standard deviation of the volatility of inflation gap and trend inflation respectively, with solid black lines show posterior mean estimates, and the thinner lines and shadowed area show the $66 \%$ confidence sets from the modeĺs posterior distribution. Source: Haver analytics and authors' calculations.

Finally, our empirical framework also provides additional information on the changes over time in the volatility of the inflation process. More specifically, in addition to the timevarying persistence in the dynamics of each of the two different components of observed inflation, the trend and the inflation gap components, our empirical analysis provides separate estimates of the stochastic volatility affecting each of those components. Allowing for the magnitude of shocks to the inflation trend and the transitory component can help understand the nature of the factors driving inflation in the different countries. Moreover, in the case of trend inflation, together with its level, the magnitude of trend shocks may shed light on the degree of anchoring of inflation expectations.

There are significant differences in the presence of stochastic volatility for trend inflation among the economies in our sample (see Figs 3-14, panels C and D). We interpret this finding as reflecting the different degree of development in the monetary policy framework of Asian economies over the last decades. As expected, a well-established monetary policy 


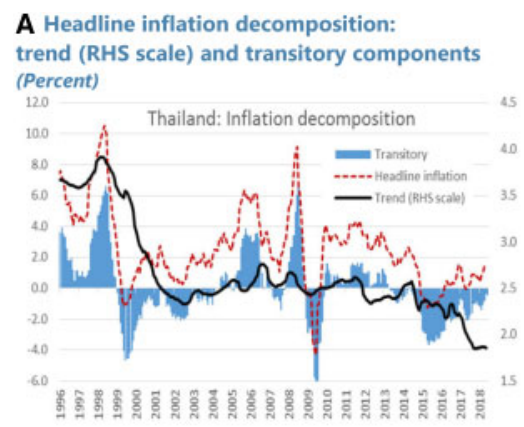

\section{Trend inflation shock: standard deviation}

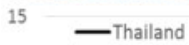

10

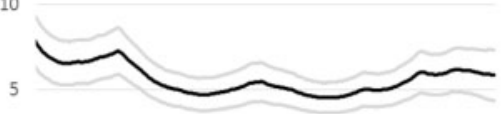

0

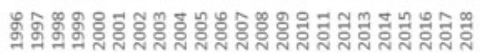

B Trend inflation (Percent)

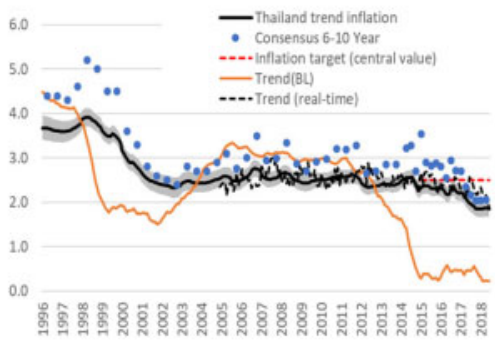

D Inflation gap shocks: standard deviation 15

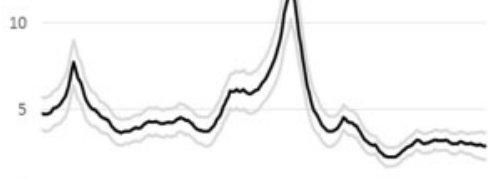

0

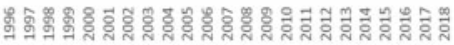

Fig. 14. Inflation analysis: Thailand. Notes: Analysis of headline inflation dynamics based on our benchmark model specification (UCSV-SUR, see Section 4 for model details). Panel A reports the decomposition of inflation into a trend (or persistent) component and the transitory (or inflation gap) component. Panel B also includes two trend inflation estimates based on the benchmark model specification, the smoothed estimates (solid black line, with shadowed area reflecting 16th and 84th quantiles), and the real-time estimates (from 2004, black discontinued line), trend inflation estimates using an alternative model (UCSV-BL, orange line) using only backward-looking information (historical inflation realizations), the level of the inflation target (or central value of the target range, red dashed line) announced by the central bank, and survey (long-term) inflation expectations from Consensus Forecasts (blue dots). Panels $C$ and $D$ show the estimated standard deviation of the volatility of inflation gap and trend inflation respectively, with solid black lines show posterior mean estimates, and the thinner lines and shadowed area show the $66 \%$ confidence sets from the modeĺs posterior distribution. Source: Haver analytics and authors' calculations.

regime seems to be associated with low volatility of trend estimates, at least over our sample. Overall, for the countries that have introduced formal inflation targets/bands as part of their monetary policy regime, trend inflation levels and the volatility of trend shocks have tended to decrease, but often after some time, reflecting the need for an adjustment period. It is then not surprising that countries with a more recent improvement of their monetary policy frameworks do display higher volatility of trend inflation in the early years of our sample. Moreover, despite a remarkable decline in trend inflation level and volatility in most EMs (e.g. China, India, Indonesia, Malaysia), there are some sizable differences in both dimensions with respect to some peer Asian countries-particularly those with wellestablished and strongly credible monetary policy frameworks and inflation targets (e.g. Australia, New Zealand)—which suggest that there is still room for improvement in their monetary policy frameworks and communication. From a modelling perspective, in general, trend volatility shocks tend to be higher when we use the univariate model UCSV-BL than our benchmark baseline model UCSV-SUR across most countries. This explains why 
this model produces highly volatile estimates of the level of trend inflation for some countries, as pointed out above, and highlights the important information content of survey long-term inflation expectations about the monetary policy regime which they bring into the trend inflation estimation.

\section{Concluding remarks}

This article shows that trend inflation analysis helps interpreting both inflation dynamics and long-term inflation expectations. By focusing on 12 of the largest Asian countries over the last three decades, it offers novel international evidence across countries in different stages of economic development, monetary policy regimes, and inflation experiences.

We discussed the challenges posed by the disinflationary pressures triggered by the sharp decline in oil prices in 2014-5 for two key aspects for monetary policy, namely, to what extent the declines in headline inflation should have been expected to be just mainly temporary, and how to interpret the reactions of long-term inflation expectations. We found significant heterogeneity across Asian economies. The case of countries that suffered from a protracted period of low and below-target inflation is particularly noticeable. Those in which trend inflation remains low but constant (e.g. Australia, New Zealand) may have low inflation only temporarily, whereas in those where trend inflation continued to decline (e.g. South Korea, Thailand) face risks low inflation becoming more entrenched. This evidence may also help better understand the challenges faced by the respective central banks when handling the unprecedented COVID-19 shock.

From a policy perspective, and particularly since many other countries have also been afflicted by a protracted period of below-target inflation over recent years, our findings for Asian countries can offer important lessons for many other central banks worldwide. In particular, the trend inflation analysis introduced in this article and the international evidence we provide on how to better interpret changes in inflation dynamics and long-term inflation expectations should be useful for the conduct of monetary policy and improving central bank communication in many other countries.

From a research perspective, the discrepancies between long-term survey inflation forecasts and trend inflation that we document in this article can provide strong motivation to investigate the role of information rigidities in survey inflation forecasts at international level. Indeed, it would be important to assess the extent to which information rigidities or other frictions documented for USA survey inflation expectations also hold for other countries.

\section{Supplementary material}

Supplementary material is available on the OEP website. These are the matlab files and the online appendix. The matlab files for this article are contained in the zip file called 'GPreplication'. We are however unable to include the associated survey dataset with the matlab files as they are proprietary. The survey data used in this article are available from Consensus Economics Forecasts and for more details please visit their website https://www.consensuseconomics.com/.

\section{Acknowledgements}

We are particularly grateful to Josh Chan, Matteo Ciccarelli, Ricardo Gimeno, Rizki Wimanda, Luca Branco, the editor Francesco Zanetti, and three anonymous referees, as well as seminar 
participants at the IMF and the ECB for useful comments and suggestions. Excellent research assistance by Qianqian Zhang is gratefully acknowledged. Errors are our responsibility. The views expressed are those of the authors and do not necessarily reflect those of the IMF and/or the ECB. This research work was initiated while Juan Angel was working at the Asia Pacific Department of the IMF, and we are very grateful for their hospitality, support and suggestions.

\section{References}

Atkeson, A. and Ohanian, L. (2001) Are Phillips curves useful for forecasting inflation?, Quarterly Review, 25, 2-11.

Bryan, M.F. and Cecchetti, S. (1994) Measuring core inflation, in N. Gregory Mankiw (ed.) Monetary Policy, University of Chicago Press, Chicago, 195-215.

Chan, J., Koop, G., and Potter, S.M. (2013) A new model of trend inflation, Journal of Business and Economic Statistics, 31, 94-106.

Chan, J., Clark, T., and Koop, G. (2018) A new model of inflation, trend inflation, and long-run inflation expectations, Journal of Money, Credit and Banking, 50, 5-53.

Cogley, T. (2002) A simple adaptive measure of core inflation, Journal of Money, Credit, and Banking, 34, 94-113.

Coibion, O. and Gorodnichenko, Y. (2012) What can survey forecasts tell us about information rigidities?, Journal of Political Economy, 120, 116-59.

Coibion, O., Gorodnichenko, Y., and Kamdar, R. (2018) The formation of expectations, inflation, and the Phillips curve, Journal of Economic Literature, 56, 1447-91.

Eckstein, O. (1981) Core Inflation, Prentice Hall, New York.

Eo, Y., Uzeda, L., and Wong, B. (2020) Understanding trend inflation through the lens of the goods and services sectors, SSRN, https://ssrn.com/abstract=3717699 or 10.2139/ssrn.3717699.

Faust, J. and Wright, J. (2013) Forecasting inflation, in G. Elliott and A. Timmermann (eds) Handbook of Economic Forecasting, vol. 2, North Holland, Amsterdam, pp. 2-56.

Fuhrer, J., G. Olivei, G., and Tootell, G. (2012) Inflation dynamics when inflation is near zero, Journal of Money, Credit and Banking, 44, 83-122.

Forbes, K. (2019a) Has globalization changed the inflation process? BIS Working Papers, No. 791.

Forbes, K. (2019b) Inflation dynamics: dead, dormant, or determined abroad? NBER Working Paper, No. 26946.

Garcia, J.A. and Dany-Knedlik, G. (2018) Monetary policy and inflation dynamics in ASEAN economies, IMF Working Papers, 18, 1.

Garcia, J.A. and Poon, A. (2018) Trend inflation and inflation compensation. IMF Working Papers, $18,1$.

Garcia, J.A. and Poon, A. (2021) What can trend inflation tells about long-term inflation expectations? ECB Working Paper Series, Forthcoming.

Garnier, C., Mertens, E., and Nelson, E. (2015) Trend inflation in advanced economies, International Journal of Central Banking, 11, 65-136.

Gordon, R. (1990) The Phillips curve now and then. NBER Working Paper, No. 3393.

International Monetary Fund. (2013) The dog that didn't bark: has inflation been muzzled or was it just sleeping?, World Economic Outlook, Chapter 3, April. Washington DC.

International Monetary Fund. (2016) Global disinflation in an era of constrained monetary policy, World Economic Outlook, Chapter 3, October. Washington DC.

International Monetary Fund. (2018a) Low inflation in Asia: how long will it last?, Regional Economic Outlook, Asia Pacific, Chapter 2, May. Washington DC.

International Monetary Fund. (2018b) Challenges for monetary policy in emerging markets as global financial conditions normalize, World Economic Outlook, Chapter 3, October. Washington DC. 
Kamber, G. and Wong, B. (2020) Global factors and trend inflation, Journal of International Economics, 122, 103265.

Kozicki, S. and Tinsley, P. (2012) Effective use of survey information in estimating the evolution of expected inflation, Journal of Money, Credit and Banking, 44, 145-69.

L'Huillier, J.-P. and Zame, W. (2014) The flattening of the Phillips curve and the learning problem of the Central bank, Technical Report, Einaudi Institute for Economics and Finance (EIEF).

Mertens, E. (2016) Measuring the level and uncertainty of trend inflation, Review of Economics and Statistics, 98, 950-67.

Mertens, E. and Nason, J. (2020) Inflation and professional forecast dynamics: an evaluation of stickiness, persistence and volatility, Quantitative Economics, 11, 1485-520.

Morley, J., Piger, J., and Rasche, R. (2015) Inflation in the G7: mind the gap(s), Macroeconomic Dynamics, 19, 883-912.

Okuda, T., Tsuruga, T., and Zanetti, F. (2019) Imperfect information, shock heterogeneity, and inflation dynamics. Centre for Macroeconomics (CFM), Discussion Papers No. 1918.

Rich, R. and Steindel, C. (2005) A review of core inflation and an evaluation of its measures, Federal Reserve Bank of New York Staff Report 236.

Stock, J. and Watson, M. (2007) Why has U.S. inflation become harder to forecast?, Journal of Money, Credit and Banking, 39, 3-33.

Wynne, M. (2008) Core inflation: a review of some conceptual issues, Federal Reserve Bank of St. Louis Review, 90, 205-28. 